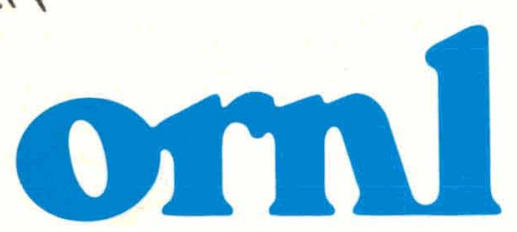

OAK

RIDGE

NATIONAL

LABORATORY

UNION

CARBIDE

\section{Radiation Effects on Organic Insulators for Superconducting Magnets \\ Annual Progress Report for Period Ending September 30, 1979}
R. R. Coltman, Jr.
C. E. Klabunde
R. H. Kernohan
C. J. Long

OPERATED BY

UNION CARBIDE CORPORATION FOR THE UNITED STATES DEPARTMENT OF ENERGY 


\section{DISCLAIMER}

This report was prepared as an account of work sponsored by an agency of the United States Government. Neither the United States Government nor any agency Thereof, nor any of their employees, makes any warranty, express or implied, or assumes any legal liability or responsibility for the accuracy, completeness, or usefulness of any information, apparatus, product, or process disclosed, or represents that its use would not infringe privately owned rights. Reference herein to any specific commercial product, process, or service by trade name, trademark, manufacturer, or otherwise does not necessarily constitute or imply its endorsement, recommendation, or favoring by the United States Government or any agency thereof. The views and opinions of authors expressed herein do not necessarily state or reflect those of the United States Government or any agency thereof. 


\section{DISCLAIMER}

Portions of this document may be illegible in electronic image products. Images are produced from the best available original document. 
Printed in the United States of America. Available from National Technical information Service

U.S. Department of Commerce

5285 Port Royal Road, Springfield, Virginia 22161

NTIS price codes-Printed Copy: A04 Microfiche A01

This report was prepared as an account of work sponsored by an agency of the United States Government. Neither the United States nor any agency thereof, nor any of their employees, makes any warranty, expressed or implied, or assumes any legal liability or responsibility for any third party's use or the results of such use of any information, apparatus, product or process disclosed in this report, or represents that its use by such third party would not infringe privately owned rights. 
ORNL/TM-7077

Contract No. W-7405-eng-26

SOLID STATE DIVISION

RADIATION EFFECTS ON ORGANIC INSULATORS FOR SUPERCONDUCTING MAGNETS Annual Progress Report for Period Ending September 30, 1979

R. R. Coltman, Jr., C. E. Klabunde, R. H. Kernohan, and C. J. Long*

Date Published: November 1979

*Metals and Ceramics Division

OAK RIDGE NATIONAL LABORATORY

Oak Ridge, Tennessee 37830

Operated by

UNION CARBIDE CORPORATION

for

DEPARTMENT OF ENERGY

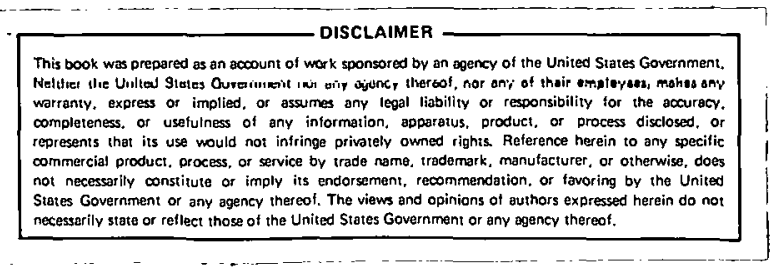


THIS PAGE

\section{WAS INTENTIONALLY \\ LEFT BLANK}


CONTENTS

Page

Abstract . . . . . . . . . . . . . . . . . . . 1

I. Introduction . . . . . . . . . . . . . . . . 2

II. Experimental Procedures and Specifications . . . . . . . . 3

A. Materials . . . . . . . . . . . . . . . . . 3

B. Types of Tests and Sample Specifications . . . . . . . . 4

C. Irradiation Conditions . . . . . . . . . . . . . . . . 7

D. Irradiation and Test Procedures . . . . . . . . . 12

III. Postirradiation Results . . . . . . . . . . . . . . . . . 14

A. Electrical Tests . . . . . . . . . . . . . . . . . 14

B. Mechanical Strength Tests . . . . . . . . . . . . . 17

1. Flexure Fracture . . . . . . . . . . . . . . . . 18

2. Linear Flexure Modulus . . . . . . . . . . . . 23

3. Flexure Strain . . . . . . . . . . . . . . . 23

4. Compression Tests . . . . . . . . . . . . . . . 23

5. Bond Tests. . . . . . . . . . . . . . . . 26

C. Color and Appearance Changes . . . . . . . . . . . . . 26

D. Dimensional Changes . . . . . . . . . . . . . . . . 33

E. Radioactivity . . . . . . . . . . . . . . . . . 36

F. Weight Loss . . . . . . . . . . . . . . . . . 38

G. Gas Evolution . . . . . . . . . . . . . . . . . 42

H. Aluminized Kapton . . . . . . . . . . . . . . . . . 44

IV. Conclusions . . . . . . . . . . . . . . . . 44

V. Acknowledgments ................. . 48

VI. References . . . . . . . . . . . . . . . . . 50 
RADIATION EFFECTS ON ORGANIC INSULATORS FOR SUPERCONDUCTING MAGNETS Annual Progress Report for Period Ending September 30, 1979

R. R. Coltman, Jr., C. E. Klabunde, R. H. Kernohan, and C. J. Long* Solid State Division, Oak Ridge National Laboratory

Oak Rịge, Tennessee

\section{ABSTRACT}

The most recent efforts in a program to study the effects of irradiation near $5 \mathrm{~K}$ on organic insulators for fusion reactors have extended the irradiation dose from $2 \times 10^{9}$ to $1 \times 10^{10}$ rads and have studied additional effects due to fast neutrons. When added to a gamma-ray dose of $2.4 \times 10^{9}$ rads, a fast-neutron fluence of $2.4 \times 10^{20} \mathrm{n} / \mathrm{m}^{2}$ has little effect upon changes in electrical and mechanical properties. At this dose, present results are in agreement with previous results. At a dose of 1 $10^{10}$ rads, particle-milled epoxies are at "end of life" in terms of mechanical strength, while fiberglass-cloth-filled epoxies retain sufficient strength for use. Electrical-resistivity and voltage-breakdown values were reduced in some materials but remained in a usable range. Two sheet-type materials showed excellent stability in their electrical properties. Dimensional stability was generally good, except for one epoxy. which showed considerable swelling at the higher dose.

*Metals and Ceramics Division. 
RADIATION EFFECTS ON ORGANIC INSULATORS FOR SUPERCONDUCTING MAGNETS R. R. Coltman, Jr., C. E. Klabunde, R. H. Kernohan, and C. J. Long

\section{INTRODUCTION}

A program is in progress at ORNL to study the effects of irradiation at liquid-He temperature on the properties of organic insulators. Its aim is to understand the irradiation behavior of materials that may be used in the construction, of large superconducting coils which provide magnetic containment for the plasma in a fusion reactor. The use of such materials, especially cast epoxies, provides an economical method for producing not only electrical insulation but also mechanical support needed in coil construction. Although many studies on the effects of radiation on organic insulators do exist, there are very few studies on the simultaneous effects of radiation and low temperatures.

Progress in the conceptual design of tokamak fusion reactors has Led to the consideration of higher plasma power densities, and hence higher irradiation dose rates to superconducting coils and their components than had first been considered. ${ }^{(1)}$ In addition, recent calculations by Santoro et al. (2) show that without additional protective shielding certain necessary blanket and shield penetrations will lead to still higher dose rates at some magnet locations. For these reasons, new irradiations were carried out to a five-times-greater dose $\left(1 \times 10^{10}\right.$ rads $)$ than that reached in our previous study. $(3,4)$ Further, previous results (ibid.) suggested that irradiation to still higher doses might well indicate an upper limit for the end-of-life dose. The combination of previous and new results might then establish a bracket for the end-of-life dose which could be narrowed by 
future testing. Information of this type would be useful in determining shield designs which, in turn, may have some bearing on coil design.

In our previous studies, the principal damaging radiation was an energetic spectrum of gamma rays arising largely from thermal-neutron capture in a Cd shield surrounding the specimens. In the tokamak application, however, in addition to gamma rays, neutrons will be present with a variety of energy spectra at many insulator locations. Up to now, there have been few studies on the irradiation of insulators near $4 \mathrm{~K}$ by fast neutrons. To examine their possible influence, the ratio of fast-neutron flux to the gamma-ray dose rate in the present experiment was increased by a factor of 17 over that in previous irradiations.

\section{EXPERIMENTAL PROCEDURES AND SPECIFICATIONS}

\section{A. Materials}

As before, the materials chosen for study were those presently in use for magnet construction and already known to have good radiation resistance at room temperature. The following list gives the material designation as used in this report and a brief description of each.

1. Stycast 2850 FT (B1ue) - Epoxy, with 7\% $24 \mathrm{LV}$ hardener; Emerson and Cuming, Inc.; an inorganically filled room-temperature-curing epoxy. 2. EPON 828 - Epoxy, with 20-pph-Z curing agent, 0.5\% Z6020 Silane couplant; She11. Chemical Company; filled with 40 wt\% 400-mesh $\mathrm{SiO}_{2}$ (good strength, but requires $80^{\circ} \mathrm{C}$ cure, followed by $150^{\circ} \mathrm{C}$ post-cure treatment). 
3. G-10 CR - National Electrical Manufacturers Association (NEMA), a heat-activated amine-catalyzed bisphenol solid type epoxy resin laminate reinforced with continuous filament E Glass fabric, silane finished; designated for cryogenic use; Spaulding Fibre Company.

4. G-10 CR (BF) - Same as No. 3, except made with boron-free E Glass.

5. G-11 CR - Same as No. 3, except that an aromatic amine-hardened bisphenol liquid-type epoxy resin is used in its fabrication.

6. Nomex 410 - Paper, type 410; E. I. Du. Pont de Nemours \& Company; aromatic polyamide (aramid) sheet.

7. Kapton H - Film; E. I. Du Pont de Nemours \& Company; polyimide film frequently used in magnets.

8. Aluminized Kapton - Type NRC-2, King-Seeley Thermos Company, used for multilayer superinsulation.

Because of a limitation on the total mass of the assembly (see Section II-C below) in the present experiment, varnish-insulated copper wires tested in the previous experiment were omitted. Also omitted was EF-527 B-stage glass-cloth-epoxy composite because of its poor mechanica1 strength after $2 \times 10^{\circ}$ rads. Aluminized Mylar, which reached end of life after the same dose, was replaced with aluminized Kapton.

\section{B. Types of Tests and Sample Specifications}

Table I shows the number of specimens used in each irradiation for each material and/or each type of test which required a specific specimen geometry. Because of space and mass limitations in the irradiation cryostat, it was necessary to use miniaturized specimens. Standard specimen 
TABLE I

SPECIMEN QUOTAS ${ }^{\dagger}$ FOR MATERIALS AND PROPERTIES

\begin{tabular}{lccccc}
\hline \multicolumn{1}{c}{ Materials } & $\begin{array}{c}\text { Electrical } \\
\text { Resistance }\end{array}$ & $\begin{array}{c}\text { Voltage } \\
\text { Breakdown }\end{array}$ & $\begin{array}{c}\text { Flexure } \\
\text { Strength }\end{array}$ & $\begin{array}{c}\text { Compressive } \\
\text { Strength }\end{array}$ & $\begin{array}{c}\text { Bond } \\
\text { Strength }\end{array}$ \\
\hline Stycast 2850 FT & 3 & 3 & 3 & 2 & 2 \\
EPON 828 & 3 & 3 & 3 & 3 & 2 \\
G-10 CR & 3 & 3 & 3 & - & - \\
G-10 CR (BF) & - & - & 3 & 2 & - \\
G-11 CR & 3 & 3 & 3 & - & - \\
Nomex 410 & 3 & 3 & - & - & - \\
Kapton H & 3 & 3 & - &
\end{tabular}

†umbers in the body of the table are the quotas used for each of two irradiations. Three unirradiated matching control specimens were tested along with each specimen group.

Note: A piece of Aluminized Kapton $38 \times 25 \times 0.025 \mathrm{~mm}$ was folded, wrapped in Al foil, and packed with each set of specimens.

designs were scaled down to fit present conditions. The details of specimen preparation and the testing devices have been given. (3-6) For the sake of completeness and later discussion, we show in Table II the nominal dimensions and average weight of each type of specimen for each material. Other tests which also utilize some of the specimens mentioned above include changes in color, appearance, dimensions, and weight which are discussed in Section III below. The percentage composition of the evolved gas mixture resulting from each irradiation of the specimen group was determilied, along with the relative radioactivity induced in each type of 
TABLE II

SAMPLE DIMENSIONS (mm) AND WEIGHTS (mg)

\begin{tabular}{|c|c|c|c|c|c|c|}
\hline \multirow[t]{2}{*}{ Materials } & \multicolumn{2}{|c|}{$\begin{array}{c}\text { Electrical } \\
\text { Resistance } \\
- \text { Disc - } \\
12.7 \times(t)\end{array}$} & \multicolumn{2}{|c|}{$\begin{array}{c}\text { Voltage } \\
\text { Breakdown } \\
\text { - Disc - } \\
19.1 \times(t)\end{array}$} & \multirow{2}{*}{ 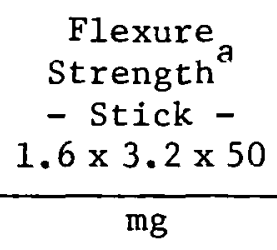 } & \multirow{2}{*}{$\begin{array}{c}\begin{array}{c}\text { Compressiye } \\
\text { Strength } \\
\text {-Cylinder- } \\
d=6.4, \ell=12 .\end{array} \\
\mathrm{mg}\end{array}$} \\
\hline & $t$ & $\mathrm{mg}$ & $t$ & $\mathrm{mg}$ & & \\
\hline Stycast $2850 \mathrm{FT}$ & $(0.38)$ & 112 & $(0.30)$ & 234 & 610 & 1075 \\
\hline EPON 828 & $(0.30)$ & 54 & $(0.30)$ & 129 & 380 & 658 \\
\hline C-10 CR & $(0.51)$ & 116 & $(0.51)$ & 261 & 432 & 763 \\
\hline $\mathrm{G}-10 \mathrm{CR}(\mathrm{BF})$ & $\cdots$ & & $-\infty$ & & 440 & --- \\
\hline$G-11 C R$ & $(0.50)$ & 111 & $(0.50)$ & 250 & 503 & 800 \\
\hline Nomex 410 & $(0.13)$ & 32 & $(0.13)$ & 73 & --- & -- \\
\hline Kapton $\mathrm{H}$ & $(0.25)$ & 23 & $(0.25)$ & 54 & --- & --- \\
\hline
\end{tabular}

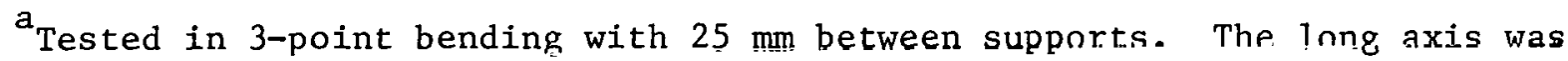
cut parallel to the warp direction from sheet stor.k for the $\mathrm{G}-10 \mathrm{CR}$, G-10 CR (BF), and G-11 CR specimens. The others were cast to size on three sides and sanded to final thickness on the fourth side, which was the compression-surface during bending.

${ }^{b}$ G-10 CR and G-11 CR specimens were cut from rods machined with their cylindrical axis parallel to the fiberglass-rloth planes, along the warp direction.

Note: Bond strength specimens were in the form of a sandwich of three $6.4 \times 6.4 \times 2.3 \mathrm{~mm} \mathrm{Cu}$ plates with two adhesive layers each $0.33 \mathrm{~mm}$ thick. Each composite specimen, weighing $2.3 \mathrm{~g}$, was machined from a large sandwich plate after curing. 
material. Electrical-resistance specimens measured in situ in the previous experiment were omitted because of the excessive mass of the necessary experimental assembly. A total of 64 specimens were used for each of the two irradiations carried out in this experiment.

\section{c. Irradiation Conditions}

As before, irradiations were made in the Low-Temperature Irradiation Facility (LTIF) located at the ORNL Bulk Shielding Reactor (BSR). To reach the dose required for this experiment in a reasonable irradiation time, it was necessary to increase the gamma-ray intensity at the LTIF over that used in the previous studies. Although the LTIF has been described elsewhere, $(3,5)$ we report here those features which provided the needed gain in dose rate and some other general features which add to the completeness of the present report.

The BSR is an open pool-type reactor suspended from a carriage which can be positioned along a movable bridge spanning the pool. With this arrangement, the reactor core can be moved to irradiation facilities such as the LTIF which are fixed in position in the pool. The schematic arrangement seen in Fig. 1-a shows the relationship of the reactor to the LTIF. During irradiation in the previous experiment, the aluminum tank of $\mathrm{D}_{2} \mathrm{O}$ which is integral to the LTIF and that at the right face of the core as seen in Fig. 1-a were placed in mechanical contact. With that arrangement, the neutron flux leaving the reactor core face becomes highly thermalized while passing through the tanks of $D_{2} O$ enroute to the cryostat of the LTIF. 


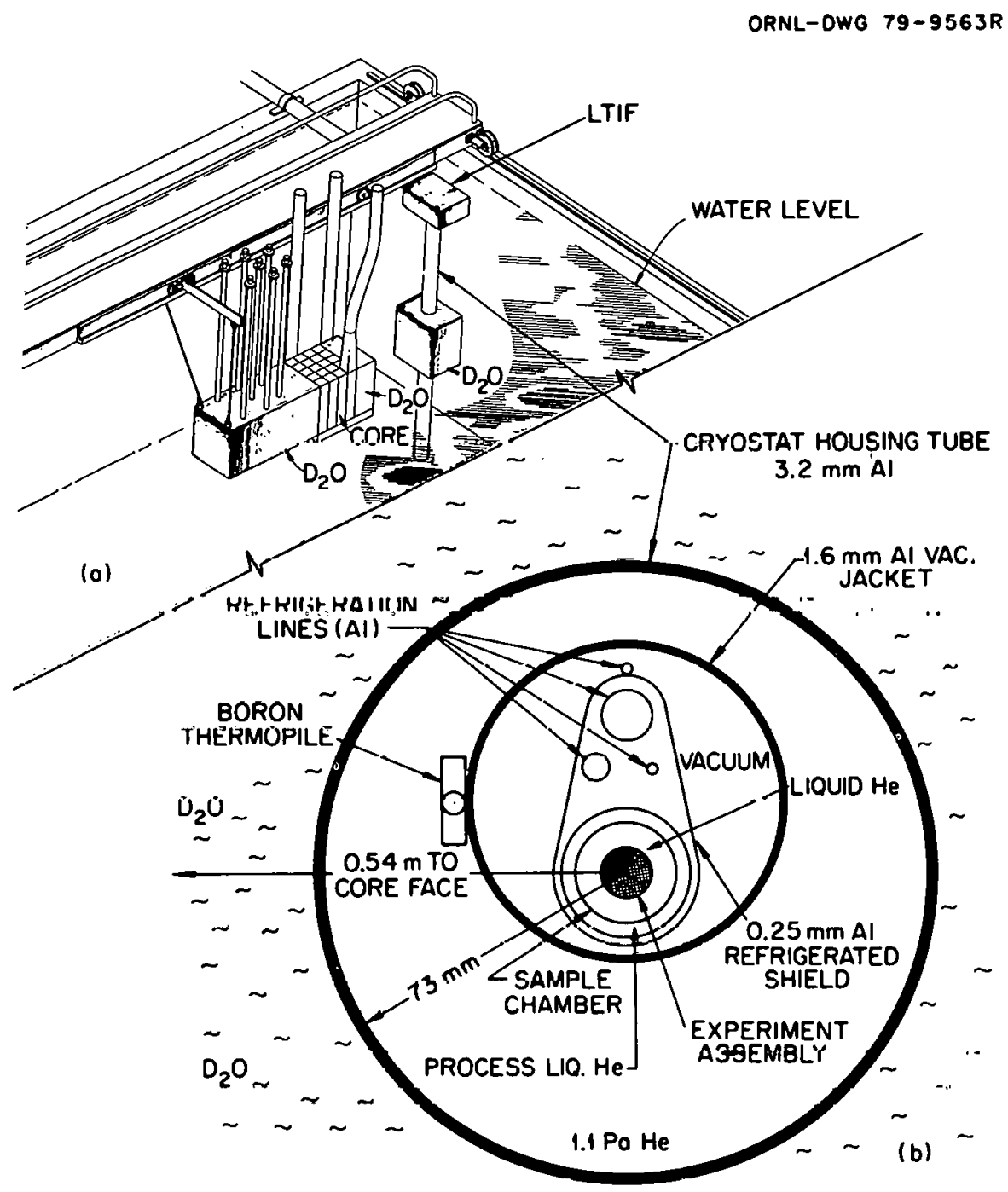

Fig. 1. (a) A schematic pictorial showing the ORNL Bulk Shielding Reactor and its relationship to heavy"water moderator and the Low... Temperature Irradiation Facility (LTIF). To enhance both the thermal- and fast-neutron fluxes at the LTIF for the present experiment, the smaller box containing $\mathrm{D}_{2} \mathrm{O}$ on the immediate right slde of the core was renoved. The right face of the core was then pleced in contact with the JTT.T.

(b) A horizontal cross-section showing the type and distribution of materials surrounding the experiment assembly. 
To increase the radiation intensity at the LTIF, the tank of $\mathrm{D}_{2} \mathrm{O}$ resting on the grid plate of the reactor core was removed, and the core face was brought directly adjacent to the LTIF for this experiment. This modification reduced the thickness of $\mathrm{D}_{2} \mathrm{O}$ between the LTIF cryostat and the face of the reactor core from 0.46 to $0.15 \mathrm{~m}$ and increased the thermalneutron flux by a factor of 4.0 and the ambient gamma-ray intensity by a factor of 4.7. To maximize the similarity in gamma-ray spectrum between previous and present experiments, the irradiated specimens were again surrounded by a cylindrical $\mathrm{Cd}$ shield. The shield converts most external thermal neutrons to gamma rays via the $n, \gamma$ nuclear reaction. The effect is to harden the gamma-ray spectrum and to further increase the intensity inside the shield. Because of its strong absorption of thermal neutrons, however, the Cd shield depresses the external thermal-neutron flux in a manner which makes it difficult to predict its contribution to the gammaray intensity inside. The amount of the depression depends on the size of the Cd shield; and, since the shield was smaller than before, it was necessary to remeasure the gamma-ray intensity in a precise replica of the present configuration. This was done in a separate test by measuring the electrical heat necessary to precisely substitute for gamma-ray heating in an aluminum cylinder at constant temperature and fixed ambient heat-exchange conditions. A value of $139 \mathrm{~mW} / \mathrm{g}$ or $5.0 \times 10^{7} \mathrm{rads} / \mathrm{h}$ was measured - 6.1 times greater than the previnus experiment.

In addition to the study of higher-dose effects, another purpose of the present experiment is to examine by comparison of present and previous results the possible influence of fast neutrons added to the same gamma-ray dose. Along with increasing the gamma-ray intensity, the reduced 
thickness of the moderator used in the present experiment produced at the same time a 100-fold increase in the fast-neutron flux at the cryostat. Measurements of the fast-neutron component indicated a spectrum similar to the ${ }^{235} \mathrm{U}$ fission-neutron spectrum, although somewhat "harder" (more high-energy neutrons), and an intensity of $1.25 \times 10^{15} \mathrm{n} / \mathrm{m}^{2} \mathrm{sec}>0.1 \mathrm{MeV} .^{\dagger}$ Comparison with corresponding values from the previous experiment shows that the ratio of fast-ncutron flux to the gamma-ray dose rate was increased by a factor of 17 in the present experiment.

$\dagger_{\text {We }}$ recognize that our measurement of the gamma-ray heating using an $\mathrm{Al}$ cylinder is in fact a measurement of the total nuclear heating, including the contribution by fast neutrons. In the case of gamma rays there is only a weak dependence of energy deposition per gram upon atomic weight. In the case of fast neutrons, however, the dependence is stronger, expecially in the range of the light elements. Using the RECOIL code, we have calculated the deposited-energy cross-section for the fissionneutron spectrum in Al to be $235 \mathrm{keV}$-barns. Multiplying this value by our fast-neutron flux (nearly a fission-neutron spectrum) and appropriate conversion factors, we estimate the rate of energy deposition in Al to be $3.8 \times 10^{4} \mathrm{rads} / \mathrm{h}$, or only $0.075 \%$ of the gamma-ray dose rate. Thus, the fast neutrons have a negligible influence on our determination of a gammaray dose rate. Because of the much greater efficiency for transfering neutron energy to $\mathrm{H}$ atoms compared to heavier atoms and because of the abundance of $\dot{\mathrm{H}}$ atoms in the organ1c materlals belng tested, however, the energy-deposition rate by neutrons is higher in them than in A1. Not knowing the specific compositions of these materials, we can make a good estimate of the upper limit of the neutron heating in them by assuming their hydrogen content is less than that for a long chain of hydrocarbon $\left(\mathrm{CH}_{2}\right)_{x}$. Since RECOIL-code calculations for $\mathrm{H}$ and $\mathrm{C}$ are not now avallable, we use a simplified calculation which integrates the product of the fissionneutron spectrum and the total neutron cross-section over the energy spectrum from 0.1 to $10 \mathrm{MeV}$. In calculating deposited energy from this result, we make another simplifying assumption of isotropic scattering which also tends to overestimace neutron to atom transferred energies (when this method was applied to $\mathrm{Al}$, we found a result $60 \%$ greater than the RECOIL result). The resulting fast-neutron energy-deposition rates in $\mathrm{CH}_{2}$, then, are calculated to be $1.8 \times 10^{5} \mathrm{rad} / \mathrm{h}$ for $\mathrm{C}$ and $1.5 \times 10^{6}$ $\mathrm{rad} / \mathrm{h}$ for $\mathrm{H}_{2}$, giving a total of $1.7 \times 10^{6} \mathrm{rad} / \mathrm{h}$, or $3.4 \%$ of our gammaray dose rate. We conclude that the contribution to the energy-deposition rate by fast neutrons in the organic materials in this experiment is greater than in $A 1$, but still small compared to the gamma-ray dose rate. 
The sample chamber of the LTIF (25 mm diam x $203 \mathrm{~mm}$ 1ong) is at the lower end of a 5.4-m vertical access tube (see Fig. 1-b). The Al walls are cooled externally by process liquid He flowing continuously in a. closed-circuit the liquefier capable of removing 40 watts at $<5.2 \mathrm{~K}$. Prior to irradiation, He is condensed in the sample chamber to a height which covers the experiment assembly. Thus, nuclear heating generated in an assembly during irradiation is transferred to the chamber wall by convection of the nonboiling liquid He.

Because of the greatly increased nuclear heating rate in the present experiment, it was necessary to minimize the mass of the experiment assembly. This was accomplished by assigning quotas (see Table I) to the groups of specimens which reduced the number of the heavier specimens and by using a light Al screen shaped into a cylindrical basket as a specimen holder which made a slip-fit inside the Cd shield. Further, experience has shown that a cylindrical shield in the LTIF sample chamber tends to spoil convective heat transfer through the liquid helium, even if the shield is a relatively good heat conductor such as $\mathrm{Cd}$. For this reason, the length of the Cd shield $(101 \mathrm{~mm})$ was also minimized. These economies yielded an experlment ássembly with a total mass of $35.2 \mathrm{~g}$ (samples $26.5 \mathrm{~g}$; Al basket $1.2 \mathrm{~g}$; Cd shield $7.5 \mathrm{~g}$ ). An irradiation temperature of $4.98 \mathrm{~K}$ was determined by the vapor pressure of the static liquid He covering the assembly. It was found in an earlier aborted experiment assembly (47 g) with a longer Cd shield that the measured irradiation temperature approached the critical. value $(5.18 \mathrm{~K})$ at a reactor power that would have required an excessive Irradiation time to reach the required dose. Irradiation with specimens immersed in the liquid phase of helium is a requisite to this program. 


\section{Irradiation and Test Procedures}

After fabrication, all shear specimens were immersed in liquid nitrogen to insure that the thermal shock would cause no damage to the epoxy-Cu bonds. Experience had shown that all other specimen types and materials withstood thermal shock with no difficulty. Except as noted in Table I, three similar specimens of each material and each type of test were irradiated in each of two irradiations, and three control specimens were held for comparisons. The control specimens were 1mmersed In liquid helium in a laboratory vessel for the same time as thal required for the higher irradiation dose. To minimize the effect of atmospheric humidity, which is known to affect some properties of the tested materials, all specimens were kept in a desiccator throughout the course of the experiment, except at times of irradiation and testing. Tests of humidity-sensitive properties such as weight change, resistance, and voltage breakdown were carried out at times of low relative humidity, usually $15-20 \%$. All samples (control and both irradiation doses) of a given type and materlal were tested during a short period on the same day.

Prior to the initial cool-down of the LTIF for each irradiation, the sample chamber was evalualed to less than $7 \mathrm{~Pa}(0.05$ torr) each of several times after backfilling with clean dry helium. Immediately after each irradiation, the liquid He in the sample chamber was removed by pumping to 47 $\mathrm{kPa}$ (350 torr) without sample warm-up above $5 \mathrm{~K}$. The liquid-He refrigerator was then turned off and the samples warmed to room temperature. This procedure allowed all radiation-produced gases released by the specimens to expand into the closed LTIF sample-chamber system without the danger of overpressure that would otherwise occur if the liquid He were allowed to 
TABLE III

SPECIFICATIONS OF IRRADIATIONS AT $4.98 \mathrm{~K}$

\begin{tabular}{|c|c|c|c|}
\hline & $\begin{array}{l}\text { Gamma-Ray } \\
\text { Dose (rads) }\end{array}$ & $\begin{array}{c}\text { Fast-Neutron } \\
\text { Fluence } \\
\left(\mathrm{n} / \mathrm{m}^{2}>0.1 \mathrm{MeV}\right)\end{array}$ & $\begin{array}{c}\text { Irradiation } \\
\text { Time } \\
\text { (Hrs) }\end{array}$ \\
\hline Low Dose & $2.4 \times 10^{9}$ & $2.2 \times 10^{20}$ & 48 \\
\hline High Dose & $1.0 \times 10^{10}$ & $8.7 \times 1.0^{20}$ & 1.9 .3 \\
\hline
\end{tabular}

remain. Twenty-four hours after termination of each irradiation, the contents of the chamber system were then pumped slowly through an external trap immersed in a laboratory vessel of liquid He where all gases except He were frozen out. The trap was then sealed off, warmed to room temperature, and the contents analyzed for percentage composition.

The specifications for two successive irradiations made on virtually identical sets of specimens under the same conditions are given in Table III. The low-dose irradiation $\left(2.4 \times 10^{9} \mathrm{rads}\right)$ was made for the purpose of studying the effect of fast neutrons by comparing results with our previouc ctudy to 2.0 y $10^{\circ}$ rade with a fast-neutron component 17 times smaller.

The postirradiation testing of electrical properties was done at room temperature, and mechanical properties at liquid-nitrogen temperature using techniques and equipment described in earlier reports. (3-6) 
ITI. POSTIRRADIATION RESULTS

A. Electrical Tests

Resistivity

The results of resistivity measurements made at room temperature are shown in the upper portion of Table IV. Because of the substandard specimen size required by this experiment, it was necessary to measure small currents pasising through the specimens to determine resistivity values. Hor specimens having high resistivity values, currents were close to the sensitivity of the equipment ( $2 \times 10^{-14}$ amps). Total variation in resistivity values within a group of this type, such as Kapton $H$, was as high as a factor of three. In contrast, variations in lower-resistivity specimens such as Stycast 2850 FT were as little as $50 \%$ :

The results in Table IV show the following main features.

a. The Stycast $2850 \mathrm{FT}$ epoxy is virtually unaffected by the irradiation; however, the absolute values are 20 to 50 times less than those in the previous experiment. $(3,4)$ The discrepancy is presently unexplained. The EPON 828 epoxy shows some decrease in resistivity with dose, but the errors associated with the measurement of the relatively high values obscure any dose-dependent behavior. The relative changes are in qualitative agreement with the previous results (ibid.).

b. Both G-10 CR and G-11 CR fiberglass materials show little change with the low dose, but significant changes with the high dose. For G-10 CR the low-dose results are in agreement with previous results.

c. Both Nomex 410 and Kapton $H$ show little change even at the high dose. The stability of the Nomex 410 results for the low dose is in 
TABLE IV

ELECTRICAL MEASUREMENTS AT ROOM TEMPERATURE

AFTER IRRADIATION AT $5.0 \mathrm{~K}$

(Each result is the average of three measurements.)

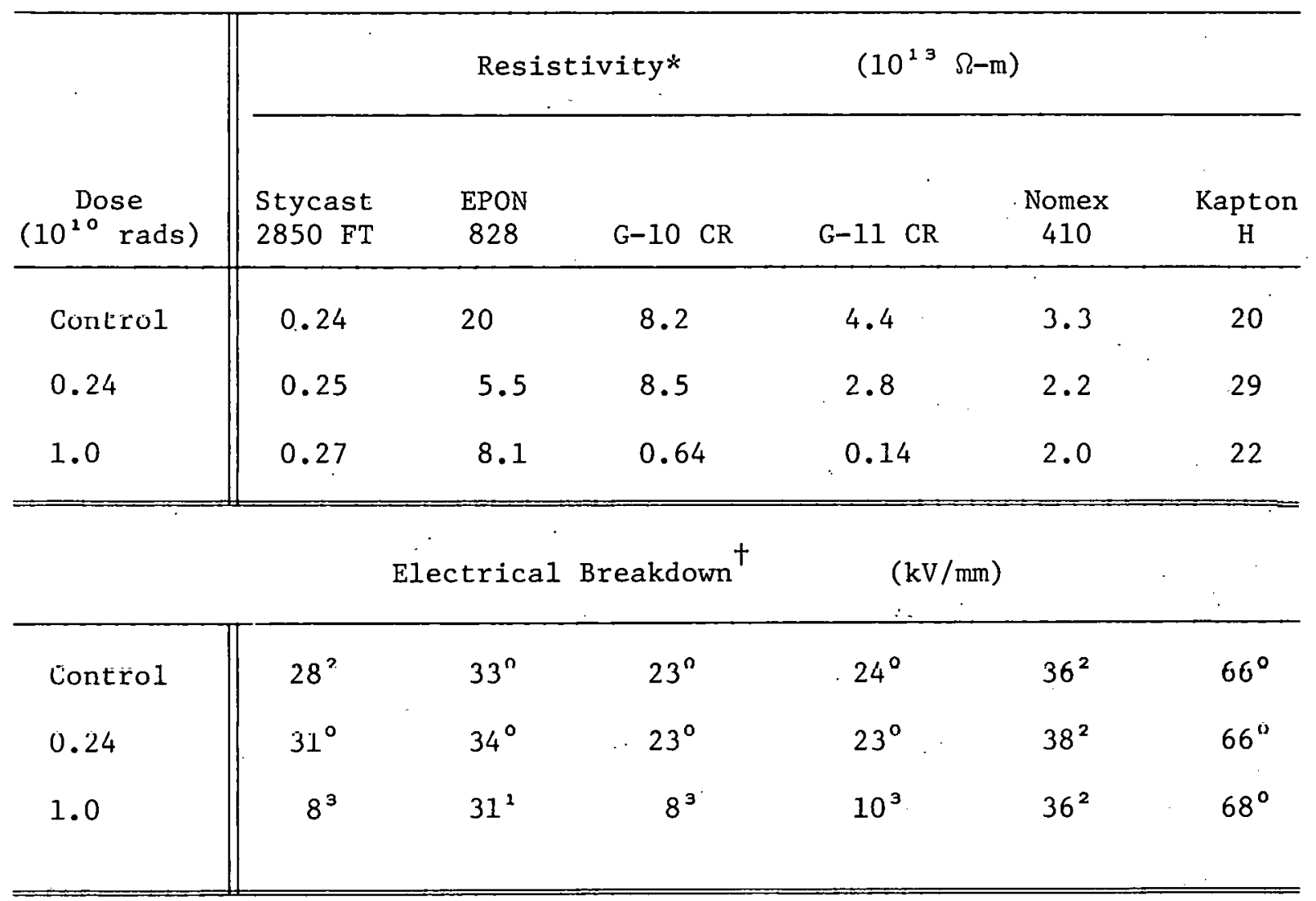

*Electrical contact was established by use of a conducting silver-filled epoxy paint. To minimize handling difficultites from radioactivity, the paint was applied after irradiation. An EMF of 100 volts was used for the resistance measurements.

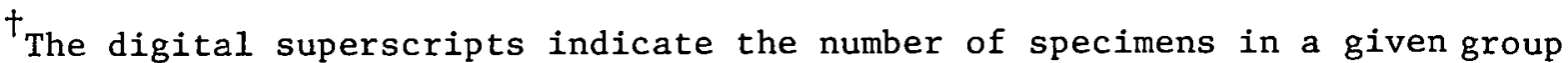
which showed a true voltage breakdown through the material in contrast to others for which a flashover around the edge of the specimen was observed. When all specimens in a given group exhibit flashover (superscript " 0 "), the true breakdown value may be significantly higher than the indicated minimum value shown. 
agreement with the previous experiment; however, as with the stycast 2850 FT, the present absolute values are about a factor of 6 lower.

When comparisons can be made with the previous results, we see no evidence that the fast-neutron fluence present in this experiment had a significant effect upon the resistivity. Further, we believe that even after the increased dose of $1 \times 10^{10}$ rads the resistivity of all materials remains in a range suitable for their intended use.

\section{Voltage Breakdown}

The results of the voltage-breakdown tests performed at room temperature are shown in the lower portion of Table IV. It can be seen that all of the materials showed little, if any, effect at the low dose. This is in agreement with the previous results, where comparisons can be made with Stycast 2850 FT, EPON 828, and G-10 CR. Further, the absolute values are also in close agreement with previous results. As with the resistivity, it appears that the fast-neutron fluence has no significant effect upon voltage breakdown at the low dose. At the high dose, the stycast $2850 \mathrm{FT}$, and both the G-10 CR and G-11 CR fiberglasses show significant drops in the breakdown voltage. The other materials show no change at the high dose. Specimens which underwent a true voltage breakdown were examined microscopically $(40 \mathrm{x})$ in the region of the "punch through." Only in one case could the breakdown be identified at this magnification with a defect such as a bubble. This does not preclude the possibility that smaller radiation defects could be responsible for lower breakdown voltages. The one case observed was in a Stycast 2850 FT control specimen where "punch through" was related to an internal bubble-casting flaw. (The least-bubble-free specimens were chosen as controls here.) 
B. Mechanical Strength Tests

For a discussion of the results of the mechanical-strength tests, which were performed with the specimens and their supporting jigs submerged in liquid nitrogen, it is important to note at the outset that the response of some materials with irradiation dose was not uniform for all types of mechanical tests performed. While a material may fail in one. test, it may survive as still useful in another test for the same dose. As a result, compromises may be necessary in choosing a material for a particular service condition.

In the case of flexure tests, the formulations given in the ANSI/ASTM D 790-71(78) code for three-point loading were utilized to obtain three types of information from recorded load-deflection curves:

fracture stress $\quad \sigma_{\mathrm{f}}=\frac{3 \mathrm{~F} \ell}{2 \mathrm{w} t^{2}}$

linear flexure modulus $\frac{\sigma}{\varepsilon}=\frac{F \ell^{3}}{4 D w t^{2}}$

flexure strain

$\varepsilon=\frac{6 D t}{\ell^{2}}$

where $\sigma=$ stress

$\ell=$ length between specimen supports $(25 \mathrm{~mm})$

$\varepsilon=$ strain

$\mathrm{w}=$ sample width

$F=$ load

$t=$ sample thickness

$\mathrm{D}=\operatorname{deflection}$

f denotes fracture.

Flexure strain was determined at tracture and at the end of the linear load-deflection behavior. (See Table II for other details on the flexure specimens.) 
In addition to the graphic results of the mechanical tests discussed below, a complete tabulation of the results for flexure, compressive, and bond (shear) strength is given in Table $\mathrm{X}$ at the end of this report.

\section{Flexure Fracture}

The fracture-stress results are shown in Fig. 2. The following are some features noted in the Fig.-2 results and others noted during the course of testing.

a. In the case of the particle-filled epoxies, the Stycast $2850 \mathrm{FT}$ showed a steady decrease in strength with dose, virtually reaching end of life at the high dose. In contrast, the EPON 828 showed virtually no change at the low dose, but it reached end of life at the high dose, indicating a sharper dose threshold for failure. Comparison of the present unirradiated and low-dose results with corresponding previous results shows no difference in radiation behavior, but present EPON 828 strengths are only about $60 \%$ of previous values for no apparent reason. The fast-neutron fluence present in the current tests seems to have had no significant effect.

b. Initially, the fiberglass-cloth-filled epoxies all have far greater strength (factor of 4 to 7 ) than the particle-filled epoxies but suffer far greater losses in strength at the low dose, with G-11 CR giving the best performance. Nevertheless, at the low dose, strengths of the fiberglasscloth-filled epoxies are equal to, or slightly better than, the particlefilled epoxies. At the high dose, the fiberglass materials suffer relatively little additional loss, making them practical candidates for use at this dose level with G-11 CR again remaining as the best performer. The closest possible comparison with previous results can be made between the 


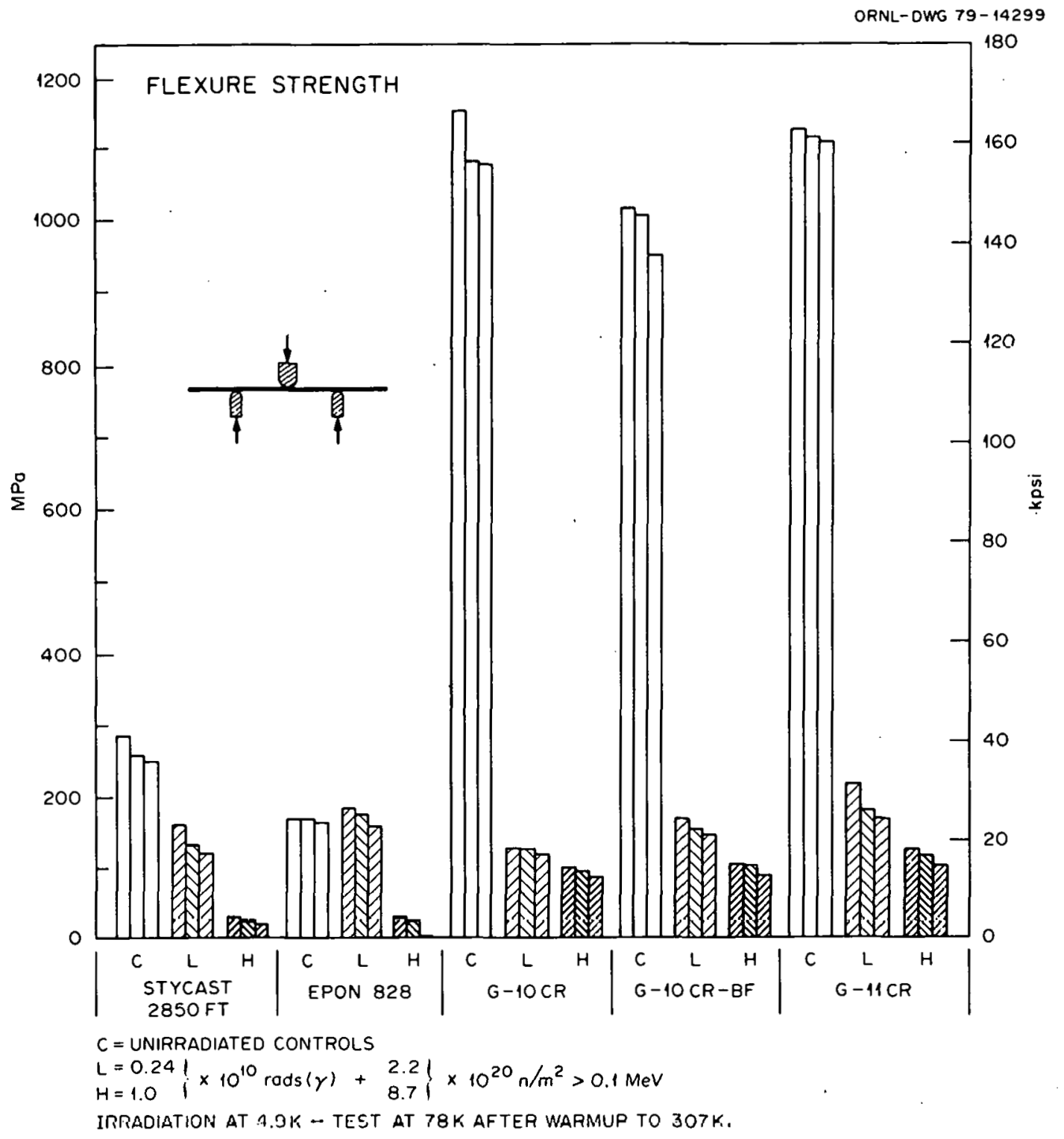

Figure 2. Flexure Strength

present G-10 CR and the previously studied G-10. While the G-10 CR had a slightly higher ( 28\%) initial strength, after the present low dose of $2.4 \times 10^{9}$ rads, its strength was about $73 \%$ that of the previously studied G-10 after a dose of $2.0 \times 10^{\circ}$ rads. Although our data on dose dependence are limited, it would seem that at least part of the difference between 
the G-10 CR and the G-10 can be based on the $\gamma$-ray dose difference, leaving little possible effect upon the G-10 CR by the fast neutrons.

c. Because of the limitation in mass of the present experiment assembly, a thinner-than-usual Cd shield was used to capture impinging thermal neutrons which thereby produce some of the gamma rays needed for the experiment. As a result, a small fraction of the thermal neutrons penetrated the Cd shield to reach specimens within. We have calculated the thermalneutron flux to be $4.7 \times 10^{15} \mathrm{n} / \mathrm{m}^{2}-\sec$ ( $\sim 3.8$ times the fast-neutron flux). While it is true that thermal neutrons can produce displacement damage in solids by means of the $n, \gamma$ reaction, the primary atom-recoil energies involved are much smaller than those for fast neutrons, and the neutroncapture cross-sections of the constituent elements in organic insulators are generally much smaller than the fast-neutron-scattering crosssections. As a result, we expect the production of damage by thermal neutrons to be comparatively negligible for materials in the present experiment, with one possible exception - materials with fiberglass containing boron. Upon capture of a thermal-neutron, ${ }^{10} \mathrm{~B}$ (20\% isotopic abundance in natural boron) fissions to produce ${ }^{7} \mathrm{Li}$ and ${ }^{4} \mathrm{He}$ fragments having a combined energy of $2.8 \mathrm{MeV}$ which can cause significant displacement damage in the vicinity of the fission event. For this reason, special boron-free fiberglass material G-10 CR (BF) was tested to compare with normal materials containing $\mathrm{B}$.

The results in Fig. 2 show that for both the low and high doses the fracture stress of G-10 CR (BF) is slightly greater than the G-10 CR which contains $B$, suggesting that $B$ may have a small deleterious effect in the present experimental conditions. A comparison between B-produced damage 
and the gamma-ray damage can be made on the basis of the rate of energy deposition. Manufacturers' specifications indicate $8-13$ wt\% (we choose $10 \%$ for this calculation) of $\mathrm{B}_{2} \mathrm{O}_{3}$ in the glass fibers or 3.1 wt\% of elemental B. Further specifications show G-10 CR to be 33.7 wt\% glass, giving $f_{B}=1.0 w t \% B$ in the composite. The energy-deposition rate in watts, then, is given by $0.01 \mathrm{~A} \sigma \phi_{\mathrm{T}} \varepsilon_{\mathrm{F}} / \mathrm{m}$ where $\mathrm{A}$ is Avogadro's number, $\sigma=760$ barns - capture cross-section of natural $\mathrm{B}, \phi_{\mathrm{T}}=4.7 \times 10^{15} \mathrm{n} / \mathrm{m}^{2}-\mathrm{sec}-$ thermal-neutron flux, $\varepsilon_{F}=2.8 \mathrm{MeV}$-fission energy, and $M=$ atomic weight of $B$. When appropriate constants are applied, we find an energydeposition rate of $0.089 \mathrm{~W} / \mathrm{g}$ or $64 \%$ of the gamma-ray dose rate. Because our data for the fiberglass materials are in a range where strength is only weakly dependent upon dose, we cannot make a precise accounting between $B$ content and strength. The calculation of energy deposition, however, is at least in qualitative agreement with the present result that irradiated G-10 CR (BF) shows slightly greater strength than G-10 CR, especially if some consideration is given to the fact that initially the G-10 CR (BF) is slightly weaker than G-10 CR (see Fig. 2). From present results, it appears that the precise influence of $B$ might best be studied in the dose range $\sim 2 \times 10^{8}-2 \times 10^{9}$ rads, where a stronger dependence on dose should occur.

It is worth noting at this point that if fiberglass materials should be chosen for use in magnet locations of a fusion reactor, then the need for B-free glass is a question for further calculation. In their neutronics calculations for fusion reactors, Santoro et al. (7) have found that the fully thermalized component of the neutron flux present in the magnet is relatively small. Because there is little hydrogenous material 
present in the magnet to provide prompt thermalization of neutrons, most neutrons are captured by magnet materials when their energies are in an epithermal range. The capture cross-section of $B$, however, decreases as $1 / E$ with increasing neutron energy, E, which effect can strongly reduce the influence of $B$ in a poorly thermalized neutron spectrum. Calculations of an effective capture cross-section for $B$ in the neutron spectra at magnet locations would be helpful in evaluating the possible need for B-free glass in these materials.

d. The failure of both unirradiated and irradiated particle-filled epoxy specimens always occurred as a nonplanar fracture mainly oriented perpendicular to the sample length. The lightly filled EPON 828 fracture surfaces were rather smooth and glass-like, while the more highly filled Stycast 2850 FT showed fine-granular fracture surfaces.

In the case of the fiberglass materials, the unirradiated specimens failed by a tearing of the tension surface at the point of maximum stress directly opposite the center loading nose (CLN). In contrast, the irradiated specimens failed by a buckling of the compression surface adjacent to the CLN as a result of delamination; i.e., fracture and separation of the epoxy matrix between glass layers. In the case of low dose, the delamination-and-buckling zone along the long axis of the specimen was quite narrow (about equal to the sample thickness) and traversed through the sample thickness along an angle of about $45^{\circ}$ away from one side of the CLN. At the high dose, the delamination zone was very broad (from 6 times the sample thickness to half the sample length), so the buckling occurred in a very slight ox-bow shape. 


\section{Linear Flexure Modulus}

The results obtained for linear flexure modulus seen in Fig. 3 show this property to be substantially less sensitive to irradiation than the flexure-fracture stress. At the high dose, the G-11 CR maintains a slightly superior position consistent with the fracture results.

\section{Filexure Strain}

The results of flexure-strain measurements made at failure and at the end of the linear or near-linear load-deflection behavior are given in Fig. 3. Generally, the results correlate with the fracture-stress results, which is consistent with the relat1vely smaller changes in modulus due to irradiation.

\section{Compression Tests}

The results of the compression tests given in Fig. 4 show three main features:

a. In general, the initial behavior with respect to material type and that with respect to dose are in close qualitative agreement with the flexure-fracture results except for one notable exception. Whereas at the high dose the EYUN 828 showed end of life in the flexure test, substantial strength remains under compression - the best performance of all materials tested.

b. The initial and low-dose compressive strengths of particle-filled epoxies are in close agreement with earlier studies, $(3,4)$ which suggests the fast-neutron fluence in the present experiment has no significant effect - in agreement with flexure-fracture results. When a comparison is made again as in III-B-1-b above we find the present G-10 CR is considerably weaker (factor of 2.5 ) than G-10 tested previously for nearly equal 

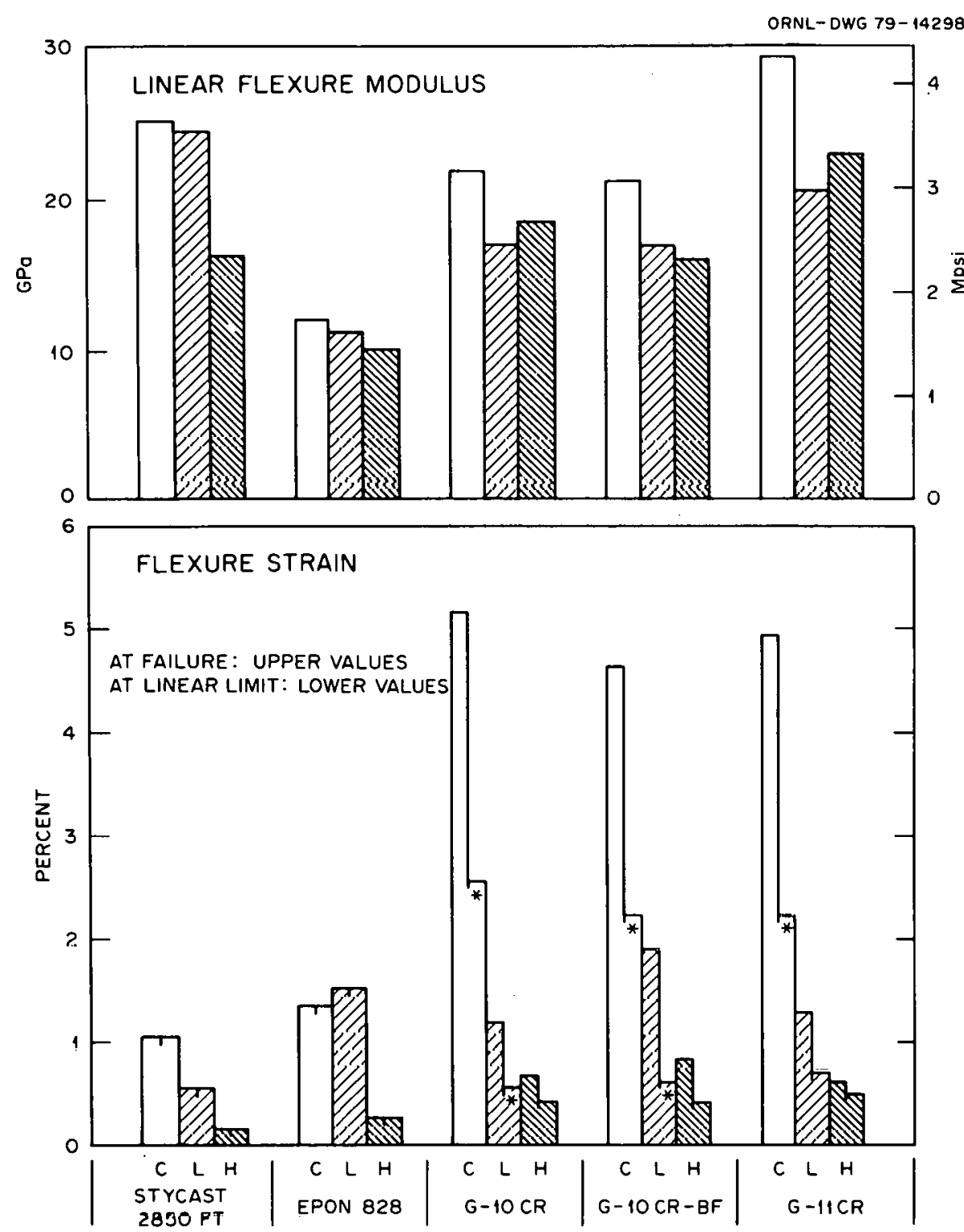

$C=$ UNIRRAUIATEO CONTROLS

$\left.\left.\begin{array}{l}L=0.24 \\ H=1.0\end{array}\right\} \times 10^{10} \operatorname{rads}(\gamma)+\begin{array}{l}2.2 \\ 8.7\end{array}\right\} \times 10^{20} \mathrm{n} / \mathrm{m}^{2}>0.1 \mathrm{MeV}$

IRRADIATION AT $1.9 \mathrm{~K}$ - TEST AT $78 \mathrm{~K}$ AFIER WARMUP TO $307 \mathrm{~K}$.

EACH RESULT IS THE AVERAGE OF 3 TESTS.

* DENOTES STRAIN AFTER 5\% CHANGE IN SLOPE OF THE LOAD-DEFLECTION CURVE WHICH WAS NONLINEAR.

Figure 3. Linear Flexure Modulus and Strain

doses. This result can be due to the fast-neutron flux or the higher thermal-neutron flux (resulting in greater B fission damage) or the combination of both in the present experiment. 


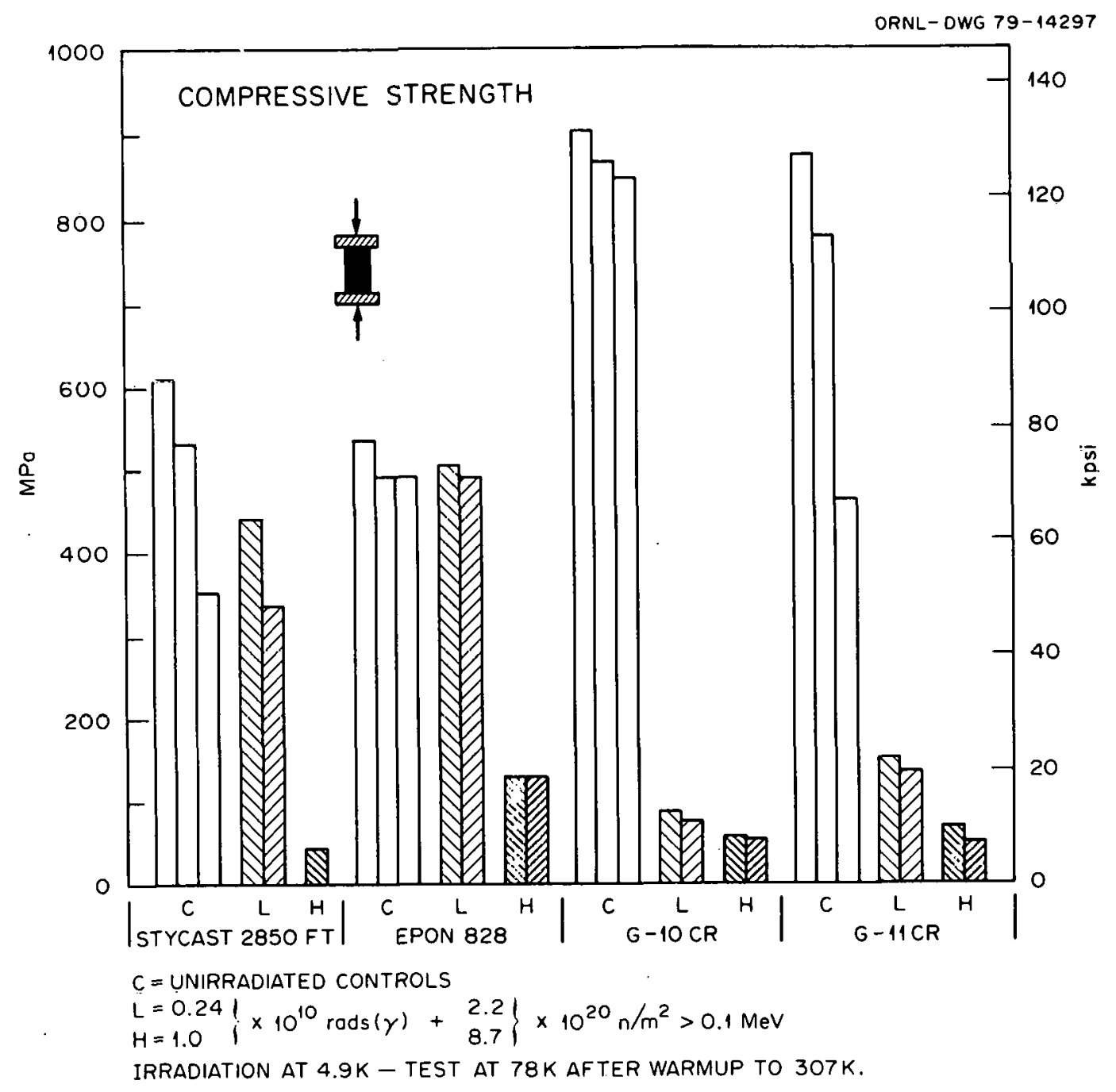

Figure 4. Compressive Strength

c. In the glass-cloth filled epoxies, only one of the two interesting orientations of this highly anisotropic material was tested. As noted in Table II,b, the cloth planes were parallel to the cylinder axis so that in testing they were under longitudinal compression. Failure (indicated by the abrupt unloading of the specimen) in the unirradiated specimens was by fracture into two or more fragments along irregular surfaces generally not parallel to the specimen axis. Some tearing and delamination effects were 
seen. The low-dose specimens remained intact but showed bands of deformation at angles to the specimen axis. The bands appear to be a series of short planar segments of fiberglass cloth which have undergone local buckling. The high-dose specimens failed by complete delamination into many planar segments parallel to the specimen axis. Some segments were slightly wedge shaped, and the onset of delamination into still thinner sections was apparent in many segments. If compression tests were done on specimens having their cloth layers oriented perpendicular to the compression axis, the results could be expected to be very different from the present tests.

\section{Bond Tests}

Shear tests of bond strength were performed on the casting materials (i.e., the particle-filled epoxies), and the results are shown in Fig. 5. In general, the initial and low-dose shear strengths are considerably higher than previous results (" factor of 3), which is believed to relate to the surface preparation of the $\mathrm{Cu}$ plates. Prior to solvent cleaning, the plates in the present experiment were thoroughly abraded with No. 180 grit paper. Up to the low dose the EPON 828 shows superior strength, but it maintains its rather characteristic sharp threshold approach to an end-of-life dose. In all tests, the primary failure is at the copper-epoxy interface, with never any tendency to produce shearbreaks in the interior of the epoxy, except perhaps in some minute areas of the very-much-weakened materials after the high dose.

\section{Color and Appearance. Changes}

The voltage-breakdown specimens were used to examine color and appearance changes in all the materials except G-10 CR (BF), for which 


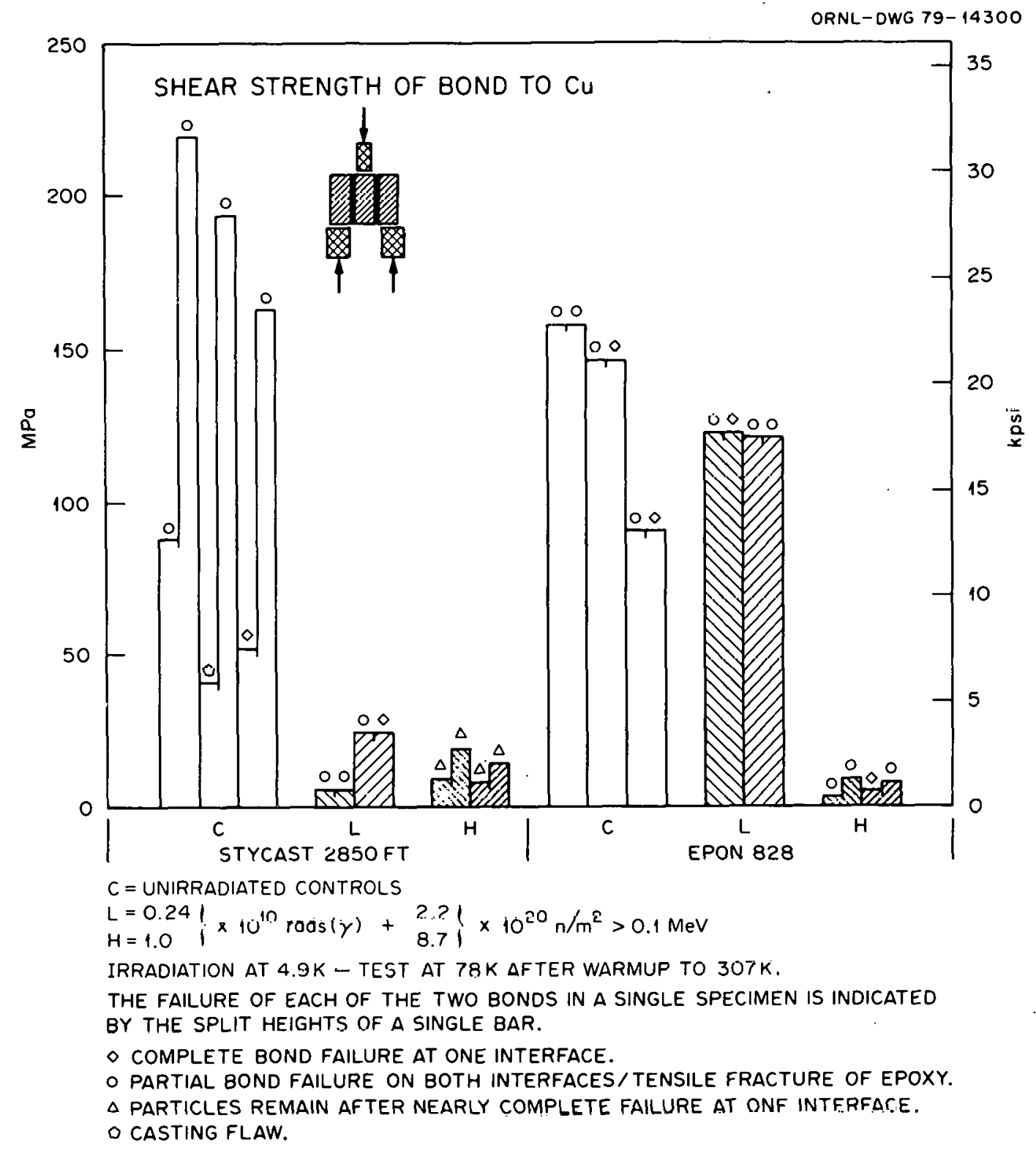

Figure 5. Bond Shear Strength to $\mathrm{Cu}$

only flexure specimens were available. Since the voltage-breakdown specimens were generally quite thin, they were useful in observing not only changes in coloration, but for some materials changes in transparency as well. Further, the transparency of some materials provided the opportunity to study some internal defects. The results shown in the Fig. -6 col.nr 
Fig. 6. ORNL-PHOTO 2214-79. The effect of irradiation upon color and transparency. Shown full scale. (Șhown on facing page.) 
VOLTAGE BREAKDOWN SPECIMENS

$$
2.4 \times 10^{9} \quad 1 \times 10^{10} \mathrm{RAD}
$$

STYCAST 2850-FT

EPON 828

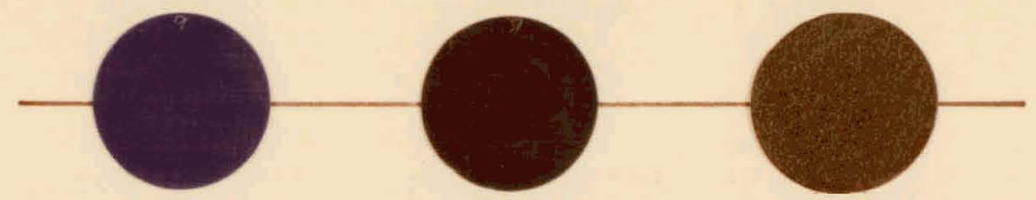

G-10CR

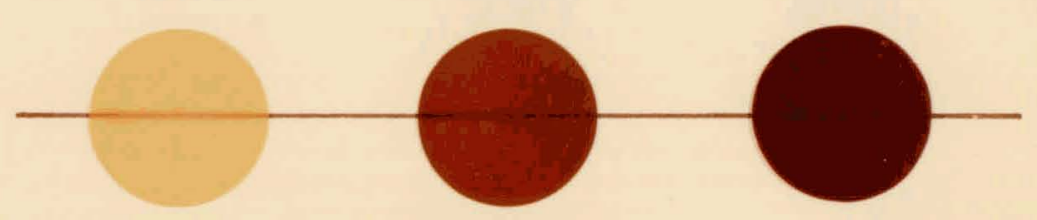

G-11CR

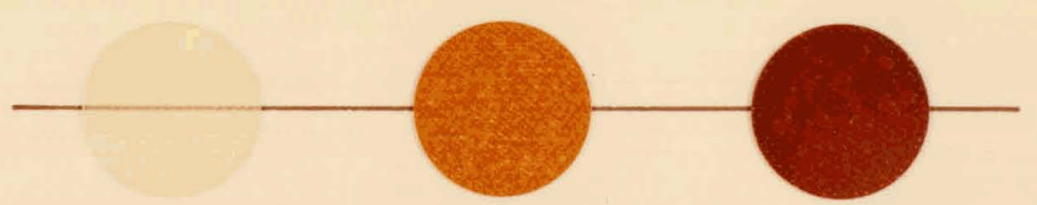

NOMEX 410

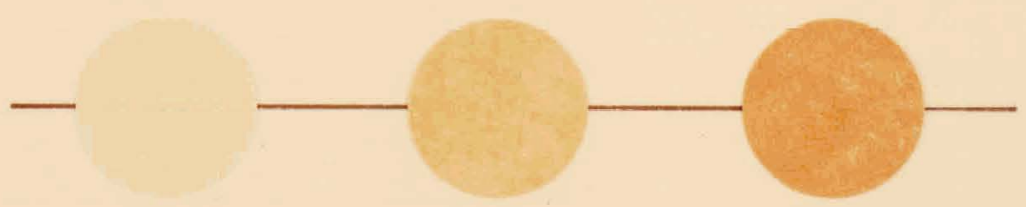

KAPTON H

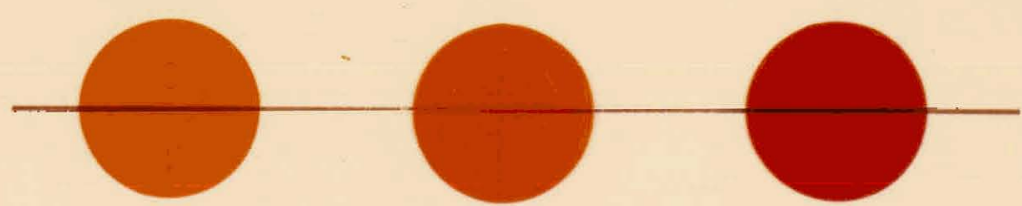

FLEXURE SPECIMENS

G-10CR (BF)

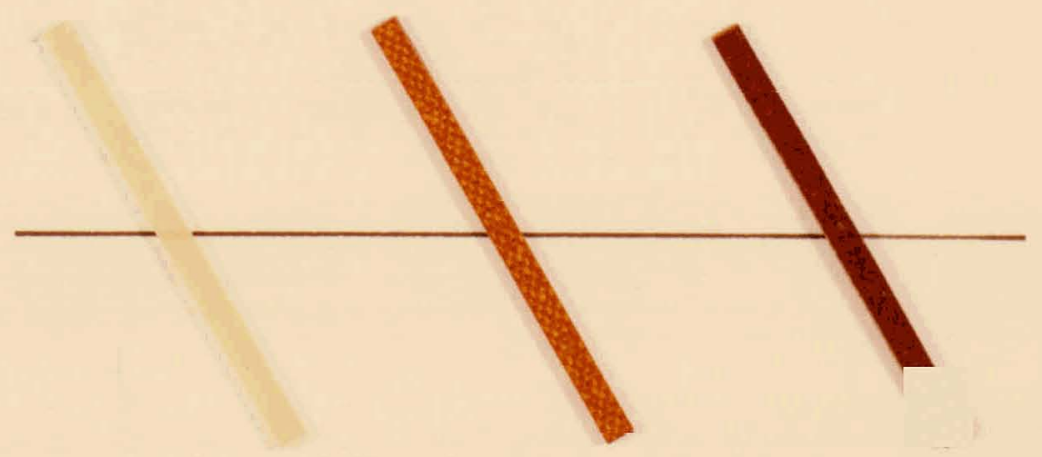


THIS PAGE

\section{WAS INTENTIONALLY \\ LEFT BLANK}


photograph are made with the specimens centered over a black line on white paper and using oblique overhead illumination. This arrangement provides the opportunity to examine changes in transparency with dose. It is interesting to note that in the fiberglass materials differences in radiation-induced coloration between the resin laminate and the glass fibers brings about a clear visibility of the weave which is not seen in the unirradiated controls.

For some materials, color changes might be useful in providing a rough estimate of irradiation dose. In particular, EPON 828 and the fiberglass materials show strong changes in coloration (darker and darker browns) throughout the dose range studied, in contrast to the modest changes seen for Nomex 410 and Kapton H. Stycast 2850 FT darkens some, but has a pronounced color change from rich blue through greenish blue to dark jade green. The possibility is recognized that color changes may have some practical value for estimating correlated changes in electrical and mechanical properties for conditions where fluence and the type of irradiation may be uncertain.

Stereomicroscope examinations of all specimens were made using magnifications up to $40 \mathrm{X}$ to look for structural defects. Except for color change, no other features could be found for any of the low-dose specimens. For the high dose, however, the particle-filled epoxy and fiberglass materials developed visible defect structures, while the Nomex 410 and Kapton $\mathrm{H}$ did not.

A11 of the high-dose Stycast 2850 FT specimens showed a finetextured surface lumpiness thought to be related to swelling. This is discussed in Section III-D. 
A11 of the high-dose EPON 828 voltage-breakdown and resistivity discs developed bubble and spot-1ike structures, as seen in Fig. 7. In each case, the structures were not uniformly distributed, but were located near a portion of the rim. Under stereomicroscopy, the large circular features appear as saucer-shaped fracture surfaces or craters in which the central material is still present and in some cases acts to slightly raise the sample surface. The small black spots appear as irregular planar regions oriented at steep angles to the surtace.

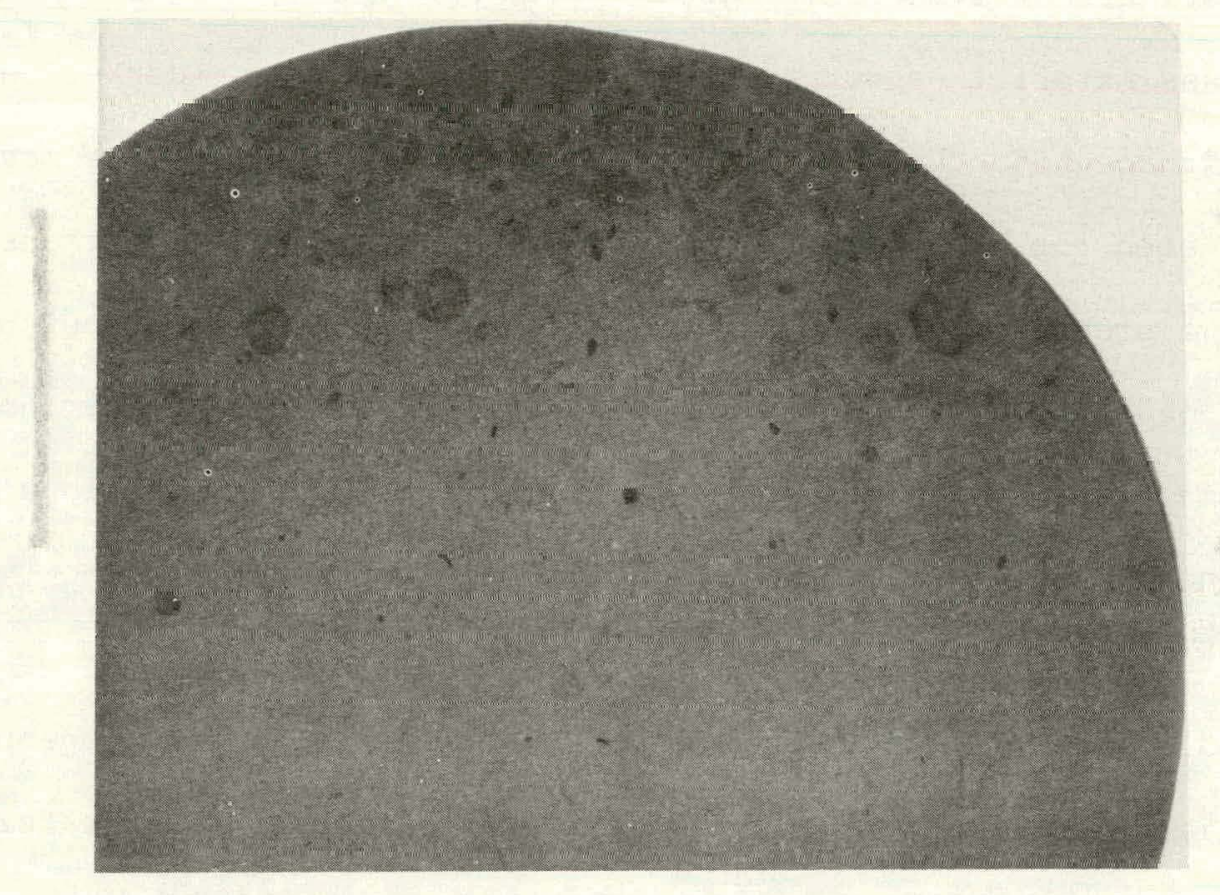

Fig. 7. An EPON 828 voltage-breakdown specimen after irradiation to $1 \times 10^{10}$ rade at $4.9 \mathrm{~K}$. Magnifiration $7 \mathrm{X}$.

In the case of the high-dose fiberglass specimens, their semitransparent qualities were an aid in seeing radiation-produced defect structures. More-or-less planar fracture surfaces were observed to occur near the perpendicular intersection of fiber elements in the weave. These are 
regions of somewhat-reduced glass content and give the appearance of a separation of the matrix from the glass fibers. In some cases, platelets produced by fracture extended upwards from the outer surface at a shallow angle but remained attached to the material. These could be flexed with a small metal pointer, and the resulting strain could then be followed along the fractured surface towards the interior of the specimen. Without flexing, the full extent of the fractured surface was not otherwise apparent. The results seem to suggest Llid fracture tends to nccur in glass-poor regions, perhaps as a result of preferential gas accumulation. This would be consistent with the delamination behavior observed during mechanical tests of the flexure and compression specimens (see Section III-B).

\section{Dimensional Changes}

'l'he major dimensions of all samples were measured with a micrometer caliper to an accuracy of $\pm 0.0025 \mathrm{~m}$. Within the accuracy of the measurements, no differences between the average dimensions of the control and irradiated specimens were found, except for stycast 2850 FT epoxy. A1thnugh this material showed no changes for the low dose, after the high dose considerable swelling, which was anisotropic will respect to the exterior dimensions, was observed. The effects are best illustrated with the flexure-specimen results which are given in Table V. The greatest swelling occurs in directions normal to the largest surfaces. In other terms, the swelling gives the appearance of a slightly inflated balloon which had an initial stick-like shape.

Further effects of the swelling in the Stycast $2850 \mathrm{FT}$ are seen in Fig. 8-a. The upper specimen in Fig. 8-a received the low-dose irradiation. It has remained straight and is virtually indistinguishable from 
TABLE V

DIMENSIONAL CHANGES IN STYCAST 2850 FT

FLEXURE SPECIMENS AFTER $1 \times 10^{10}$ RADS

\begin{tabular}{|c|c|c|}
\hline & $\begin{array}{c}\text { Dimen } \\
(\mathrm{mm})\end{array}$ & $\begin{array}{c}\text { Change } \\
(\%)\end{array}$ \\
\hline Length & 50 & 4.9 \\
\hline Width & 3.2 & 19.5 \\
\hline Thickness & 1.6 & 24.0 \\
\hline
\end{tabular}

an unirradiated control specimen. The remaining three shown in different positions received the high-dose irradiation. Note their longer length, bowing, and wavy surfaces compared to the upper specimen. The surface seen on the specimen second from the top was sanded after casting in a threesided mold to bring the specimen to a final dimension. Under low magnification after the high-dose irradiation, it showed a pitted structure. In contrast, the other side (an as-cast surface - third from the top) showed blistering. A bubble-like appearance was found with "bubble" sizes ranging from 0.02 to $0.7 \mathrm{~mm}$, quite visible to the naked eye, as seen by the mottled pattern in Fig. 8-a. Figure 8-b shows different views of the highdose-irradiated compressive-strength specimen of this material. A puffy appearance resembling that of the flexure specimens can be seen. of particular interest is the impression made on the sample by the adjacent Al screen sample holder used during irradiation. While the swelling of these samples must have resulted in some pressure against the surroundings, the screen could not have sustained any large pressure. It is not clear why, or at what stage during the experiment, the specimen surface became so easily impressionable. Apparently, the radiation-induced swelling of 

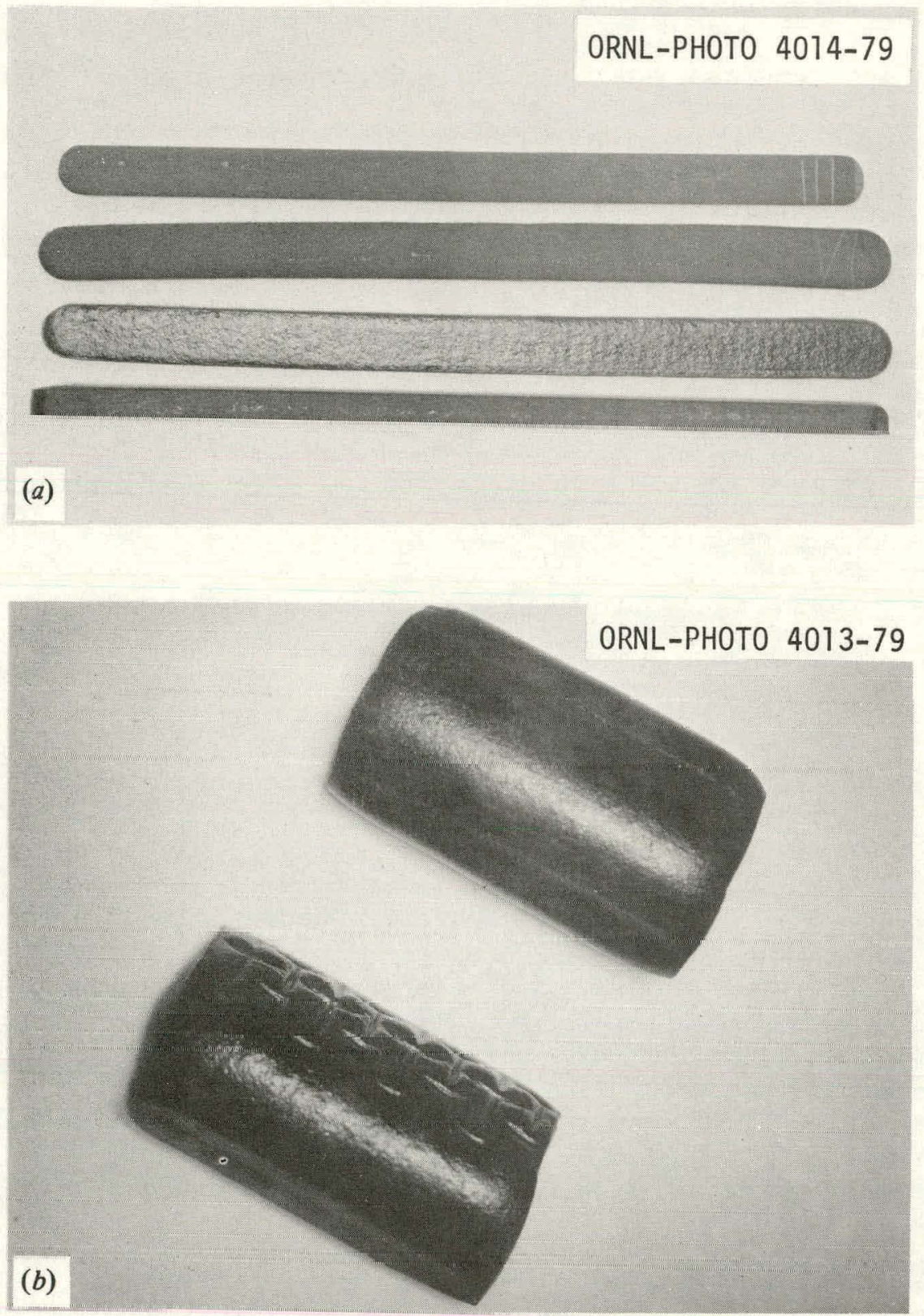

Fig. 8. (a) Stycast 2850 FT flexure specimens after irradiation at $4.9 \mathrm{~K}$. The top specimen received $2.4 \times 10^{9}$ rads, which produced no detectable dimensional changes. The remining three are different views of specimens which received $1 \times 10^{10}$ rads.

(b) Stycast 2850 FT compression specimens after $1 \times 10^{10}$ rads at $4.9 \mathrm{~K}$.

Stycast 2850 FT can be impeded locally by very small restraining pressures. Fourteen weeks after the irradiation a room-temperature creepindentation test was performed on pieces of flexure-test specimens to further examine this behavior. Local stresses of 4 to $12 \mathrm{MPa}(0.6-1.7$ 
kpsi) applied for 5 to 6 days produced indentations of 10 to $25 \%$ of the thickness in high-dose material, while in unirradiated material at $12 \mathrm{MPa}$ no creep indentation resulted.

Although this material showed considerable swelling, its weight loss was no greater than for the three fiberglass materials (see Section III-F). We cannot be certain whether the swelling is due to greater gas production in this material and much more remains trapped inside, or whether normal amounts of evolved gas left voids or cracks prior to escaping.

\section{E. Radioactivity}

The radioactivity of several materials was monitored for some weeks following the high-dose irradiation. Since the origin of the radioactivity is not known for each material (some activity may be the result of impurities, and more than one radioactive species may be present), we cannot report the results in terms of the specific activation of particular nuclear species. Instead, the results are given in the practical terms of $\mathrm{mrad} / \mathrm{hr}$ measured at the surface of a 75-mm-diameter paper-shell Cutie Pie (radiation-survey meter). Use was made of the flexure specimens for these measurements, since all were packed adjacent to one another in the sample basket, and therefore they received the same fluence. Further, their stick-like shape was more suitable for accurate positioning parallel to the barrel of the meter.

The sample activation is attributable to the leakage of thermal neutrons through the $0.13-\mathrm{mm}$-thick Cd shield surrounding the specimens. While most thermal neutrons are captured by the shield and converted to 
gamma rays, some penetrate the shield and some others enter through the open top end for a total leakage of $8 \%$ of the external isotropic neutron flux.

The results seen in Table VI show that for equal volumes the radioactivity of the standard fiberglass materials is about $20-25$ times greater than that of the particle-filled epoxies, while the boron-free fiberglass's activity is only about 6 times greater. It can also be noticed that, while all three fiberglass materials decay with the same ha1f-1ife after the first 2 weeks, before that time the rate of decay of the $\mathrm{G}-10 \mathrm{CR}$ is greater than $\mathrm{G}-11 \mathrm{CR}$. The reduced activity of the $\mathrm{BF}$

TABLE VI

RADIOACTIVITY OF FLEXURE SPECIMENS

$(\operatorname{mrads} / \mathrm{hr}) *$

\begin{tabular}{|c|c|c|c|c|}
\hline \multirow{2}{*}{ Material } & \multirow{2}{*}{$\begin{array}{l}\text { Specimen } \\
\text { Wt (mg) }\end{array}$} & \multicolumn{3}{|c|}{$\begin{array}{l}\text { Weeks After High- } \\
\text { Dose Irradiation }\end{array}$} \\
\hline & & 1 & 2 & $4 \frac{1}{2}$ \\
\hline Stycast $2850 \mathrm{FT}$ & 615 & 7 & - & - \\
\hline EPON 828 & 378 & 7 & - & - \\
\hline$G-10 \mathrm{CR}$ & 430 & 150 & 52 & 24 \\
\hline$G-10 \mathrm{CK}(\mathrm{BT})$ & 505 & 16 & 24 & 13 \\
\hline G-11 CR & 430 & 140 & 95 & 49 \\
\hline
\end{tabular}

*Measured at the surface of 75-mm-diam paper-shell Cutie Pie (radiation survey meter). 
fiberglass over the standard is not due to the absence of boron, since the neutron activation of this element produces a radioactive isotope, ${ }^{12} \mathrm{~B}$, which has only a $20-\mathrm{ms}$ half-life. The difference in radioactivity must be attributed to other differences in composition between the two types of glass.

\section{F. Weight Loss}

All control and irradiated samples (except shear specimens) were weighed before and $4 \frac{1}{2}$ weeks after irradiation on an analytic balance with a sensitivity of $0.1 \mathrm{mg}$. To account for changes in weighing conditions between the pre- and postirradiation weighing sessions, the average change in weight for a group of control samples (those of a particular type and material) was algebraically subtracted from the average change in the corresponding irradiated group to yield the net change due to irradiation. The results, whlch are presented as percent loss, are shown in Table VII. The average deviations indicated in the table were computed by further averaging the separate average deviations obtained for each material group belonging to the same sample type. Results for the resistance- and voltage-breakdown types were further combined because of their close similarity in geometry and weight.

An important parameter upon which the results depend is the surfaceto-volume ratio, $\mathrm{S} / \mathrm{V}$, of the various sample types. Average S/V values are listed in Table VII for the flexure and compressive-strength samples, while a range of values is listed for the combination of resistance- and voltage-breakdown samples. The range of values does not result from different $S / V$ values for the two sample types, which are quite small, but 
TABLE VII

WEIGHT LOSS (\%)

\begin{tabular}{|c|c|c|c|c|c|c|}
\hline \multirow{3}{*}{ Material } & \multicolumn{6}{|c|}{ Specimen Type } \\
\hline & \multicolumn{2}{|c|}{$\begin{array}{c}\text { Resistance } \& \\
\text { Voltage Breakdown }\end{array}$} & \multicolumn{2}{|c|}{ Flexure Strength } & \multicolumn{2}{|c|}{$\begin{array}{c}\text { Compressive } \\
\text { Strength }\end{array}$} \\
\hline & Tow & Iligh & Low & High & Low & High \\
\hline Etycaot $2850 \mathrm{FT}$ & 0.34 & 1.51 & 0,28 & 1...38 & 0.11 & 1.35 \\
\hline BHON 028 & 0.02 & 1.00 & 0.11 & 0.95 & חי & 0.73 \\
\hline $\mathrm{G}-10 \mathrm{CR}$ & 0.46 & 1.70 & 0.45 & 1.69 & 0.21 & 1.45 \\
\hline G-10 CR (BF) & 一 & - & 0.28 & 1.66 & - & - \\
\hline $\mathrm{G}-11 \mathrm{CR}$ & 0.41 & 1.98 & 0.39 & 1.89 & 0.18 & 1.54 \\
\hline Nomex 410 & 0.60 & 0.41 & 一 & - & - & - \\
\hline Kapton $\mathrm{H}$ & 0.12 & -0.38 & 一 & 一 & - & - \\
\hline Avg. Doviation (\%) & & & & & & \\
\hline$\sim \mathrm{s} / \mathrm{V}\left(\mathrm{mm}^{-1}\right)$ & 4.2 & 15.9 & & & & \\
\hline
\end{tabular}

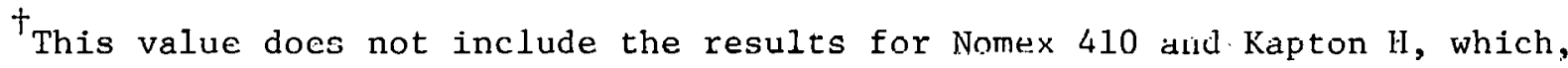
as a group, have a larger average devlaliun of $10.34 \%$ because of their sma11er weightis (see Table II).

rather because of differences in thickness of the materials. Further justification for combining the results of the resistance- and voltagebreakdown types is that the dependence of weight loss upon S/V, while significant for lower values, becomes weak in the high-range values characteristic of the resistance- and voltage-breakdown specimens. (See discussion below.) 
The following are some noteworthy features of the weight-loss results.

1. Comparison of the present with previous results obtained for a similar dose, but with a ratio of fast-neutron to gamma-ray intensity smaller by a factor of 17 , can be made for only three materials. ${ }^{3,4)}$ The Stycast 2850 FT and EPON 828 epoxies indicated somewhat higher weight loss in the previous experiment, while Nomex 410 showed the opposite effect. Losses in both experiments were small (no more than $0.6 \%$ ), and the results are barely outside of experimental error. We conclude that the additional fast-neutron fluence present in this experiment had little effect on weight loss for these three materials.

2. In spite of the greater scatter in the data for Nomex 410 and Kapton $\mathrm{H}$, it is safe to conclude that for the high dose their weight loss is less than all other materials studied, and further that Kapton $\mathrm{H}$ is probably more resistant to weight loss than Nomex. We believe the data are not accurate enough to establish the nature of the dependence of weight loss on dose for these two materials.

3. For both the high and low doses and for all sample types, the wcight loss of EPON 828 is consistently less than the Stycast epoxy and the Lhree rypes of fiberglass. The latter four all show quite similar weight losses for the same dose and the same sample type.

4. In Table VIII, we show the ratio of the weight loss for the high dose to that for the low dose for all sample types and materials except Nomex and Kapton. Except for the EPON 828, the table shows that for specimen types with all but the lowest $S / V$ value the weight-loss ratios are in fair agreement with each other, and further their average, 
TABBLE VIIT.

RATT.O OF HIGH-DOSE TO LOW-DOSE WEIGHT LOSS

(Ratio of High to Low Irradiation Dose $=4.2$ )

\begin{tabular}{|c|c|c|c|}
\hline \multirow[b]{2}{*}{ Material } & \multicolumn{3}{|c|}{ Specimen Type } \\
\hline & $\begin{array}{l}\text { Resistance } \& \\
\text { Voltage Breakdown } \\
\mathrm{S} / \mathrm{V}=4.2 \text { to } 15.9\end{array}$ & $\begin{array}{c}\text { Flexure } \\
\text { Strength } \\
\mathrm{S} / \mathrm{V}=\mathbf{1 . 9 3} \\
\end{array}$ & $\begin{array}{c}\text { Compressive } \\
\text { Strength } \\
\mathrm{S} / \mathrm{V}=0.75 \\
\end{array}$ \\
\hline $\begin{array}{l}\text { Stycast } \\
2850 \mathrm{FT}\end{array}$ & 4.4 & 4.9 & 12.3 \\
\hline EPON 828 & $50^{\dagger}$ & 8.6 & 9.1 \\
\hline $\mathrm{G}-10 \mathrm{CR}$ & 3.7 & 3.8 & 6.9 \\
\hline G-10 CR (BF) & - & 5.9 & - \\
\hline $\mathrm{G}-11 \mathrm{CR}$ & 4.8 & 4.8 & 8.6 \\
\hline
\end{tabular}

1.6, is till guod agrooment with the duse ratio of 4.2 . Ill contract, the weight-loss ratio for the specimen type with the lowest S/V value (compressive-strength specimens) is consistently higher by an average factor of 2. The origin of this result lies in the fact that, at the lnw dóse, Lle weight loas for a low $\mathrm{S} / \mathrm{V}$ configuration is markedly less than for the higher S/V configurations; whereas, at the high dose, the weight loss is roughly independent ol $\mathrm{j} / \mathrm{V}$ for the rnnge we have studied (see Table VII).

It is presumed that weight loss occurs as the result of gas atoms and molecules which diffuse out through the surface of the specimen during the postirradiation warm-up and holding period at room temperature. 
The influence of $\mathrm{S} / \mathrm{V}$ seen in the present results might be explained in terms of diffusion-produced gas bubbles and the strength of the material. For low S/V samples, the opportunity to form bubbles is greater, since the average path length of a diffusing gas atom or molecule out of the sample is greater than for high $\mathrm{S} / \mathrm{V}$ values. For small doses, bubbles formed in low $S / V$ samples can be retained hecause of their relatively low gas pressure and sufficient material strength to prevent micro-crack formation. At higher doses, however, it is suggested that bubble pressure is increased and material strength is reduced sufficiently to effectively increase the S/V ratio by the formation of micro cracks. These can then provide paths for gas atoms. to reach the surface and escape.

\section{G. Gas Evolution}

The percentage weight composition of the gas mixture evolved from all samples during warm-1.p to room tẹmerature after irradiation is given in Table IX. The same procedure described in Section II-D was used for each irradiation. It can be noted in Table IX that the off-gas composition changes with increasing dose. While the $H_{a}$ content remails fairiy constant, the $\mathrm{CH}_{4}, \mathrm{H}_{2} \mathrm{O}$, and $\mathrm{CO}_{2}$ contents show significant decreases, while $\mathrm{N}_{2}+\mathrm{CO}$ and the hydrocarbons show compensating increases. It was also found that the pressure rise in the sealed-off gas trap during warm-up to room temperalure after removal from the liquid-He bath was approximately proportional to the irradiation dose. This suggests that the amount of evolved gas is roughly proportional to the irradiation dose within the range studied in this experiment. From the compositional analysis, we have calculated the effective nolecular weight of the gas mixture for the high 
TABLE IX

ANALYSIS OF EVOLVED GASES

(Wt \%)

Dose (rads)

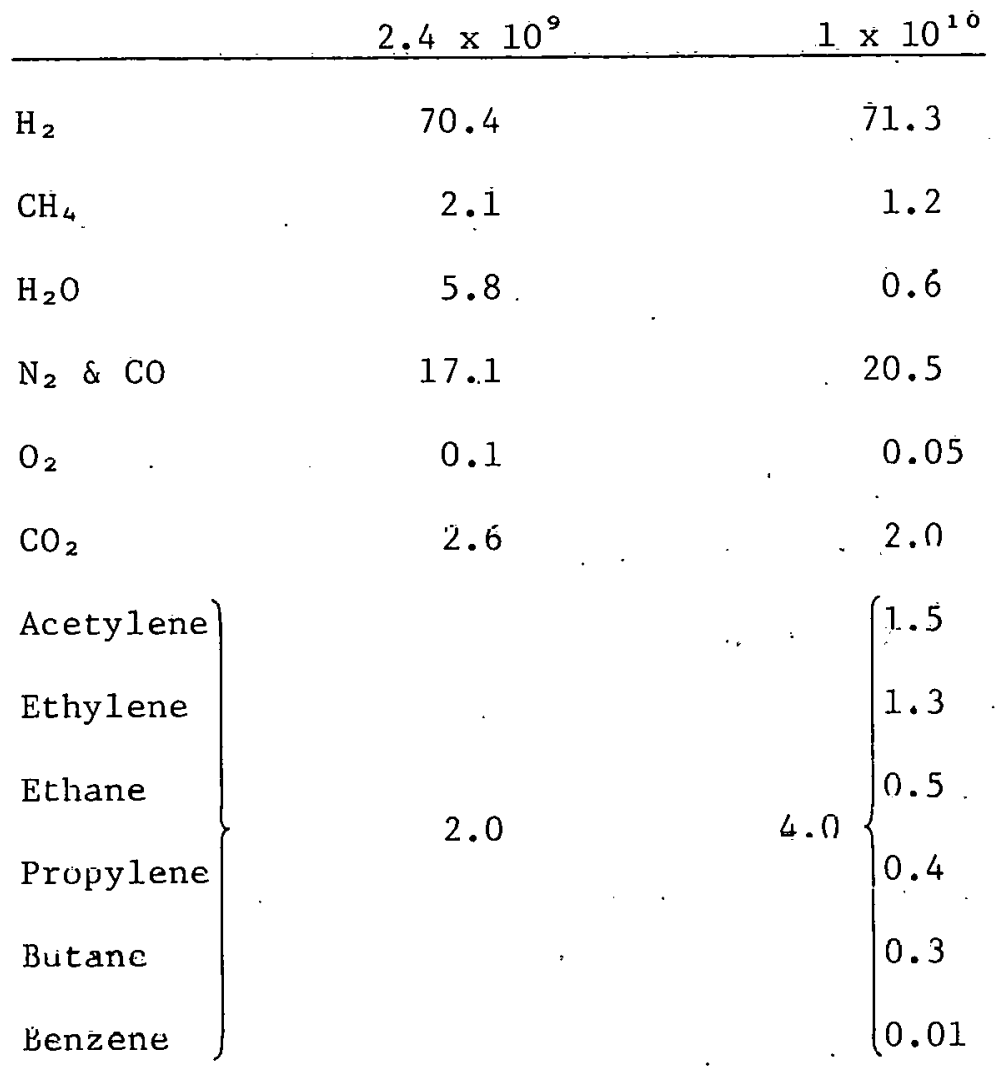

dose and then the amount of gas in the trap, using the simple gas law. We find a value that is $21 \%$ of the rnmbined weight loss of all samples meas-

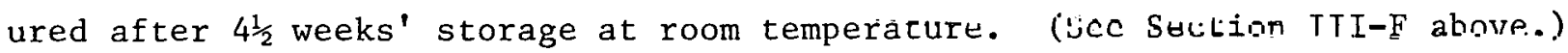
Thus, $79 \%$ of the gas evolves after the first 24 hours if we assume gas evolution is the unly wcight-loss mechanism. We recall from the previous experiment $(3,4)$ that the composition of gas evolved at later times is noticeably different from the early release, going in the direction of higher abundance of heavier molecules. 


\section{H. Aluminized Kapton}

Pieces of aluminized Kapton $37.5 \times 25 \mathrm{~mm}$ were each folded in a $\mathrm{Z}$ fashion, heavily creased, and then wrapped in Al foil to give a flat packet $\sim 13 \times 25 \mathrm{~mm}$. After irradiation, the specimens were unwrapped and compared. No differences between the control and low-dose $\left(2.4 \times 1.0^{9}\right.$ rads) specimens col1t be found. This is in sharp contrast to aluminized Mylar, which broke apart upon handling after a dose of $2.0 \times 10^{9}$ rads. $(3,4)$ The high-dose specimen of Kapton showed a very faint darkening consistent with the results seen in Fig. 6. A comparison of the samples, using a simple scraping test on the Al film, gave the impression that the high-dose specimens were slightly more susceptible to abrasion than the others. No failure of any type was observed in any of the specimens after repeated flexing of the creases. Although emissivity measurements were not made, the general appearance gave no indication that this property was changed. Overall, it appears that this material could serve as superinsulation for cryogenic systems at least up to a dose of $1 \times 10^{10}$ rads. Further, in a service of this type where large areas of film would be irradiated, the minimal outgassing of this material on warm-up, as suggested by the weight-loss results for uncoated Kapton (see Section III-F), is another desirable feature.

\section{CONCLUSIONS}

1. With regard to the electrical properties, the resistivity, which decreased substantially at the high dose, probably still remains in a usable range for all materials tested. The loss in voltage-breakdown 
strength was minimal except for Stycast 2850 FT and the glass-cloth-filled epoxies, which might require design adjustments for use at $1 \times 10^{10}$ rads. 2. In the case of mechanical properties, we find that the dependence of strength upon dose is different for flexure and compression strengths. The result suggests that the choice of a material may depend upon the stress conditions in service. Our previous results ${ }^{(3,4)}$ showed that for $2 \times 10^{8}$ rads neither property underwent significant change. In the case of flexure, we find in the present experiment that, while the strength of glass-cloth-filled epoxies is greatly reduced at $2.4 \times 10^{\circ}$ rads over initial values, they remain competitive with the strength of the particle-filled epoxies for that dose. The far superior strength inftially and at low dose of the glass-cloth-filled epoxies over the particle-filled epoxies could be useful for some low-dose-rate service locations. Because of the large drop in the strength of these materials between $2 \times 10^{8}$ and $2 \times 10^{9}$ rads, however, their best utilization requires a morc detailed study of the dependence of strengll upon dose in this raige. $\Lambda t 1 \times 10^{10}$ rads, the flexure strength of the particle-filled epoxies is at "end of life," while the glass-cloth-filled epoxies retain usable strength. 3. In the case of cumprcaoion, we find that 1nilially the glass:lucli-fillod epnxies are only moderately stronger than the particle-filled epoxice in contrast to a much larger ditterence iu the caes of flexure strength. After $2.4 \times 10^{9} \mathrm{rads}$, huwsier, their compression strength is reduced to only about one-seventh the initial value, making them considerably weaker than the particle-filled materials, which showed little or no change for the same dose. At the high dose, the compression strength of all materials is reduced to possibly barely useful levels; EPON 828 retains the greatest strength. 
4. A comparison of the present results for $2.4 \times 10^{9}$ rads $(\gamma)$ and $2.2 \times 10^{20} \mathrm{n} / \mathrm{m}^{2}>0.1 \mathrm{MeV}$ with previous results for $2.0 \times 10^{9}$ rads $(\gamma)$ and $1.3 \times 10^{19} \mathrm{n} / \mathrm{m}^{2}>0.1 \mathrm{MeV}$ suggests that an increase by a factor of 17 in the fast-neutron dose rate has little, if any, effect upon the results at the doses studied. The significance of this conclusion depends upon whether the ratio of fast-neutron to gamma-ray dose rates, $n / \gamma$, found in fusion-reactor magnet locations is comparable to the ratio in the present experiment.

Santoro et al. have calculated damage-production and gamma-rayheating rates in magnet materials at various locations in the toroidalfield coils of a tokamak. (2) Atomic-displacement damage produced by fast neutrons is expressed in terms of dpa (displacements per atom). This is determined by first calculating the neutron spectrum and intensity at a point of interest and then applying displacement theory with the appropriate nuclear data through use of a computer code, RECOIL. (2) We have applied the same computer code to the fission-neutron spectrum (which closely resembles the spectrum in the present experiment) to one of the materlals they considered $(\mathrm{Cu})$ in order to determine a corresponding dpa rate for the fission-ncutron spectrum. Within the accuracy that present theory can accommodatc variations in neutron spectra, we can then express Santoro et al.'s results in terms of equivalent fission-neutron flux. In the case of gamma rays, they calculated heating-rate values which can be converted directly for comparison with ours. 
Fur a magnet location adjacent to an injector-beam penetration (position $4^{\dagger}$ ), which gave the highest dpa and gamma-ray heating rates that Santoro et al. calculated, we find their equivalent $n / \gamma$ value to be $2 \frac{1}{2}$ times greater than that in the present experiment. We believe that this difference is small enough that the present results on the influence of fast neutrons are meaningful for some magnet locations where organic insulators will find use. If the penetration is not adjacent, which is the Cise for many other magnet locactons, thell thity find fast-ncutron and gamma-ray dose rates are reduced by different factors which give equivalent $\mathrm{n} / \gamma$ values 30 times greater than that in the present experiment. A further check of Santoro et al.'s calculations at other magnet locations indicates still higher $\mathrm{n} / \gamma$ values. While the present neutron results are meaningful for some magnet locations, we belleve that at least cursory studies to check the influence of fast neutrons should be carried out using irradiation sources having higher $n / \gamma$ sources than we have used.

$$
\text { 5. Suntoro et al.'s rcaulte (2) show that varions magnet locations }
$$
encompass a wide range of gamma-ray dose rates, the highest being adjacent to penetrations. From their results, we calculate that our high dose of $1 \times 10^{i 0}$ raris, at which some materials reached end of 11 e, correspumls by first-wall loading of only $0.2 \mathrm{MW} \mathrm{y} / \mathrm{m}^{2}$ at their "position 4" location adjacent to a penetration and $50 \mathrm{MW} \mathrm{y} / \mathrm{m}^{2}$ if the penetration is absent. Thus it is clear that in some locations additional shielding w1ll be necessary if some of these materials are to be used. In the case of the glasscloth-filled epoxies which may be considered still useful at $1 \times 10^{10}$ rads,

\footnotetext{
tPosition 4 is located on the corner of a magnet turn (square cross-section) adjacent to an injector-beam penetration. See Ref. (2).
} 
further testing at still higher doses is indicated. The same is true for Nomex 410, Kapton $\mathrm{H}$; and aluminized Kapton, all of which showed good stability at this dose. The testing of the mechanical properties of Nomex 410. and Kapton $\mathrm{H}$, which are available in other than film or sheet form, should be considered in future work to determine theix potential as structural tnaterials for use at high doses.

\section{ACKNOWLEDGMENTS}

We appreciate very much the assistance of J. M. Shoopman and L. T. Ratcliff of Oak Ridge National Laboratory during specimen preparation and testing. 
TABLE $X$

COMPLET $\Xi$ TABULATED RESULTS FOR FLEXURE, COMPRESSIVE, AND BOND (SHEAR) STRENGTH

(MPa)

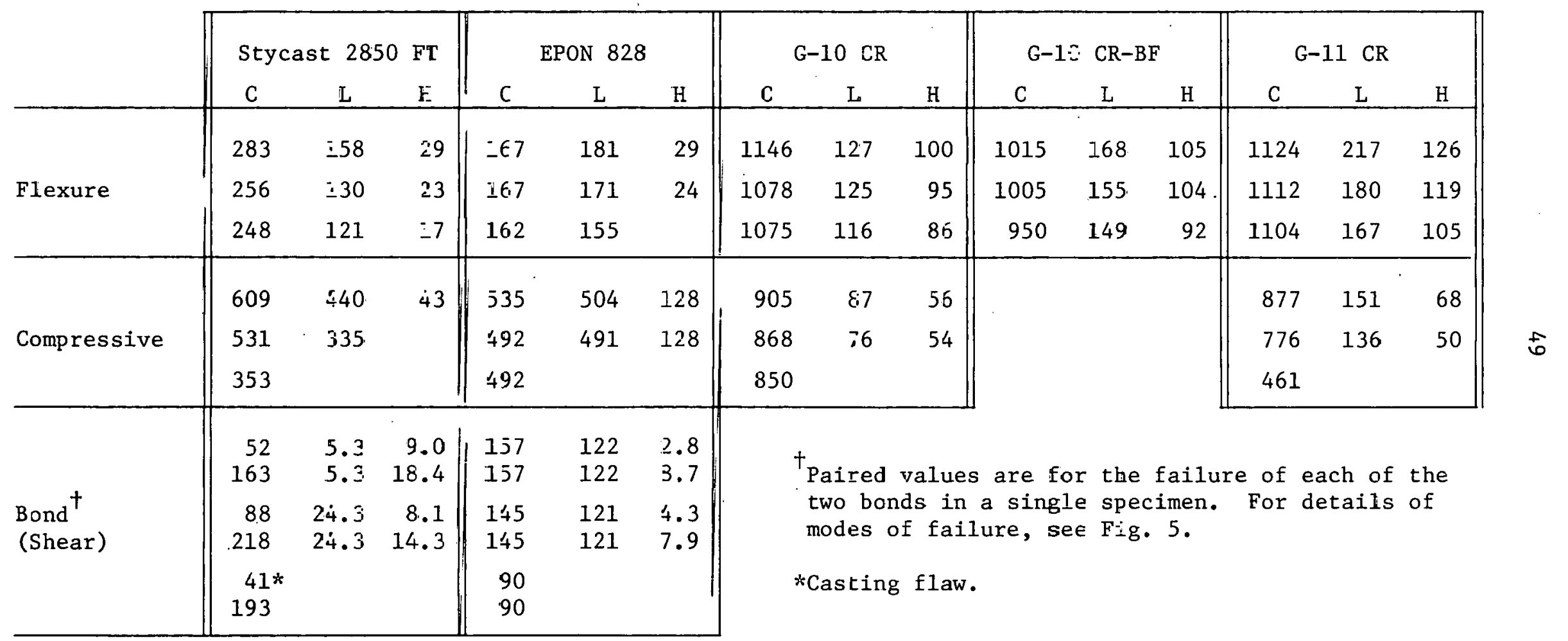

$\mathrm{C}=$ Unirradiated Contrals

$\left.\begin{array}{l}\mathrm{L}=0.24 \\ \mathrm{H}=1.0\end{array}\right\} \times 10^{10}$ rads $\left.(\gamma)+\begin{array}{l}2.2 \\ 8.7\end{array}\right\} \times 10^{20} \mathrm{n} / \mathrm{m}^{2}>0.1 \mathrm{MeV}$

Irradiation at $4.9 \mathrm{~K}$ - Test at $7.8 \mathrm{~K}$ after warmup tc $307 \mathrm{~K}$ 
VI. REFERENCES

1. J. F. Guess, R. W. Boom, R. R. Coltman, Jr., and S. T. Sekula, "A Survey of Radiation Damage Effects in Superconducting Magnet Componenls and Systems," OKNL-TM-5187, Oak Ridge National Laboratory, November 1975.

2. R. T. Santoro, J. S. Tang, R. G. Alsmiller, Jr., and J. M. Barnes, Nuc1. Tech. 37, 65 (1978).

3. R. H. Kernohan, R. R. Coltman, Jr., and C. J. Long, "Radiation Effects on Organic Insulators for Superconducting Magnets," Annua.1, Progress Report for Period Ending September 30, 1978, ORNL-TM-6708, Oak Ridge National Laboratory, March 1979.

4. R. H. Kernohan, C. J. Long, and R. R. Coltman, Jr., "Cryogenic Radiation Effects on Electric Insulators," First Topical Meeting on Fusion Reactor Materials, January 29-31, 1979, Miami Beach, Florida. To be published in J. Nucl. Mater.

5. R. H. Kernohan, R. R. Coltman, Jr., and C. J. Long, "Radiation Effects on Insulators for Superconducting Magnets," Annual Report, ORNL-TM-6193, Oak Ridge National Laboratory, January 1978.

6. C. J. Long, R. H. Kernohan, and R. R. Coltman, Jr., "Radiation Effects on Insulators for Superconducting Magnets," Proceedings of the International Cryogenic Materials Conference: Special Seminar on Nonmetallic Materials and Composites at Low Temperatures, Munich, Ccrmany, July 10-11, 1978, Plenum Press, New York.

7. R. T. Santoro, V. C. Baker, and J. M. Barnes, Nucl. Tech. 37, 274 (1978). 


\section{INTERNAL DISTRIBUTION}

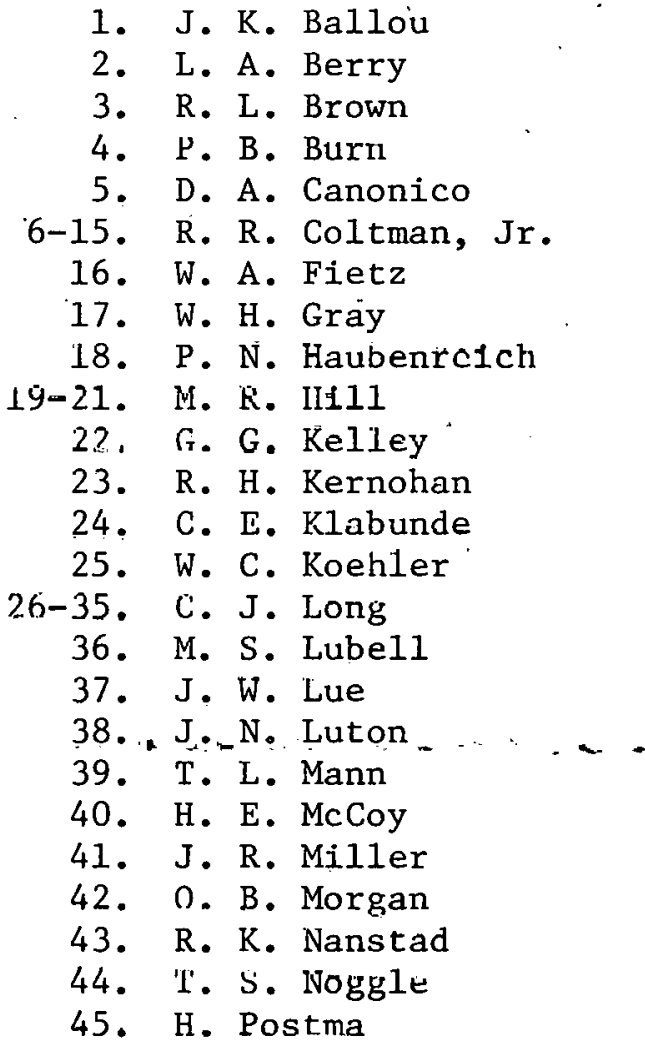

46. M. W. Rosenthal

47. T. L. Ryan

48. R. T. Santoro

49. J. L. Scott

50. S. T. Sekula

51. T. E. Shannon

52. G. M. Slaughter

53. D. Steiner

54. W.C.T. Stoddart

55. P. B. Thompson

56. D. B. Tranger.

b/. P. L. Walstrom

58. J. R. Weir, Jr.

59. M. K. Wilkinson

60. J. M. Williams

61. H. T. Yeh

62. F. W. Young, Jr.

63. A. Zucker

64-65. Centra1 Research L̀ibrary

66. Document Reference Section

67-69. Laboratory Records Department

70. Laboratory Records, ORNL R.C.

71-72. Fusion Energy Division Library

73. Fusion Energy Division Reports Office

74-83. Solid State Division Records

84. ORNL. Patent Office

EXTERNAL DISTRIBUTION

85-111. Technical Information Center, P. 0. Box 62, Oak Ridge, Tennessee 37830

11.2. Aosistant Manager, Energy Research and Development, DOE-ORO

113. J. R. Benzinger, Spaulding Fibre Company, Inc., 310 Whee1.er Street, Toniwanda, New York. 141.50

114. R. W. Boom, 513 Engineering Research Building, University of Wisconsin, Madison, Wisconsin 53706

115. B. S. Brown, Materials Science Division, Argonne National Laburatory, Argonne, Illinois 60439

116. J. L. Christian, General Dynamics/Convair, San Diego, Calif. 92112

117. J. F. Clarke, ETM DOE, Mail Stop G-234, Washington, D. C. 20545

118. F. W. Clinard, Jr., Los Alamos Scientific Laboratory, Los Alamos, New Mexico

119. M. M. Cohen, ETM DOE, Mail Stop G-234, Washington, D. C. 20545

120. D. Cohn, MIT Fusion Center, 167 Albany Street, Cambridge, Massachusetts 02139

121. E. J. Croop, Westinghouse Research and Development Center, 310 Beulah Road, Pittsburgh, Pennsylvania 152.35 
122. E.N.C. Dalder, ETM DOE, Mail Stop G-234, Washington, D. C. 20545

123. D. Damiano, Intermagnetics General Corporation, New Kainer Road, Guilderland, New York 12084

124. F. R. Fickett, National Bureau of Standards, Boulder, Colorado 80302

125. S. A. Gause, Engineering Manager, Micarta Division, Westinghouse Electric Corporation, Hampton, South Carolina 29924

126. R. Hancox, UKAEA, Culham Laboratories, Abingdon, Berks, England

127. C. D. Henning, Lawrence Livermore Laboratory, Livermore, California

128. M. B. Kasen, National Bureau of Standards, Boulder, Colorado 80302

129. F. Mazandarany, Energy Systems Department, General Electric Company, Schenectady, New York 12345

130. C. Miller, E. I. du Pont de Nemours and Company, PPR Department, Room D 6133, Wilmington, Delaware 19898

131. R. P. Reed, National Bureau of Standards, Boulder, Colorado 80302

132. L. Snead, Brookhaven National Laboratory, Upton, New York 11973

133. J. L. Young, Westinghouse Electric Corporation, Box 10864, Pittsburgh, Pennsylvania 15236

134. K.S.C. Young, Plasma Physics. Laboratory, Box 451, Building $1 \mathrm{~K}$, Princeton, New Jersey 08540

135. K. M. Zwilsky, ETM DOE, Mail Stop G-234, Washington, D. C. 20545 